\title{
Utilization of Heavy Metal Complexes As Phosphorogenic Sensors for the Detection of Amino Acids, (A Review)
}

\section{ARUMUGAM RAMDASS ${ }^{1}$, VEERASAMY SATHISH ${ }^{2 *}$ and POUNRAJ THANASEKARAN ${ }^{3 *}$}

${ }^{1}$ Research Department of Chemistry, Aditanar College of Arts and Science, Tiruchendur - 628 216, India. ${ }^{2}$ Department of Chemistry, Bannari Amman Institute of Technology, Sathyamangalam - 638 401, India. ${ }^{3}$ Institute of Chemistry, Academia Sinica, Taipei 115, Taiwan.

Corresponding author E-mail: ptsekaran@yahoo.com, vsathish1985@gmail.com

http://dx.doi.org/10.13005/ojc/340101

(Received: December 23, 2017; Accepted: January 12, 2017)

\begin{abstract}
The use of phosphorogenic heavy-metal complexes has emerged as an attractive platform for luminescence sensing and cellular imaging studies as a result of several merits including precisely arranging the coordination structures and charge-transfer characteristics. This review intends to provide the design principles and the applications of amino acids sensing based on heavy-metal complexes such as Re(I)-, Ru(II)-, Ir(III)-, and Pt(II). These metal complexes function as phosphorogenic sensors with superior activities and selectivities towards amino acids by utilizing several mechanisms, including luminescent responses of "switch-on". Furthermore, the practical utility of long lifetime and cell permeability of these metal complexes allows to detect luminescence imaging of amino acids in living cells without interference from endogenous fluorophores.
\end{abstract}

Keywords: Amino acids, Cell imaging, Heavy metal complexes, Phosphorescence, Selectivity.

\section{INTRODUCTION}

Amino acids that are bioactive molecules play pivotal roles in maintaining various biological pathways in cellular functions. Especially, biothiols such as cysteine (Cys) homocysteine (Hcys) and reduced glutathione (GSH) are responsible for the physiological balance in living system ${ }^{1-3}$. The abnormal levels of these thiols are linked to a number of human diseases, such as cancer, slow growth, edema, liver damage, cardiovascular, Parkinson's disease, Alzheimer's disease, skin lesions, etc ${ }^{4,5}$. Therefore, typical instrumental detection techniques include colorimetric

This is an Open Access article licensed under a Creative Commons Attribution-NonCommercial-ShareAlike 4.0 International License (https://creativecommons.org/licenses/by-nc-sa/4.0/), which permits unrestricted NonCommercial use, distribution and reproduction in any medium, provided the original work is properly cited. 
detection ${ }^{6}$, electrophoresis ${ }^{7}$, electrochemical assay $^{8}$, high-performance liquid chromatography ${ }^{9}$, Fourier transform infrared (FTIR) spectroscopy ${ }^{10}$, mass spectrometry ${ }^{11}$, and UV-Vis spectrophotometry ${ }^{12}$ have been developed and applied for the detection of thiol containing amino acids but they require relatively complicated and multistep reactions, and sophisticated instrumentation.

An alternative technique, fluorescence method exhibits a lot of advantages such as high sensitivity, easy operation, rapid detection, low cost, highly efficient, real-time analysis and easily visualized analysis technique for the detection and quantification of amino acids. Therefore, numerous organic fluorophores have been prepared by modifying their rich chemical structures, and widely used them as probes to detect these amino acids Via change in the signal of fluorescence ${ }^{13-15}$. However, most of these fluorophores suffer from low photostability, poor water solubility, interference from background fluorescence, scattered light in real-time applications, short excitation wavelength, and the small stokes shift. Hence, the development of excellent probes without these drawbacks is highly desired for enabling the wide spread use of sensors that can be applicable to various amino acids.

The introduction of heavy metal ions such as $\mathrm{Pt}(\mathrm{II})$-, $\mathrm{Ru}(\mathrm{II})-, \operatorname{Re}(\mathrm{I})$-, $\operatorname{Ir}(\mathrm{III})$ - ions into the organic fluorophores was found to be dramatically changed in their emission characteristics. Special features of heavy metal complexes include: high photo-, thermal-, and chemical- stabilities, visible absorption and emission wavelengths, large Stokes shifts, long excited-state lifetimes, signal discrimination from short-lived background fluorescence Via spectral and temporal resolution and low cytotoxicity. These excited state properties usually depend on the available metal centers, structure and triplet state of the ligands, and their environments, and associates with intraligand charge-transfer (ILCT), ligand-to-ligand chargetransfer (LLCT), ligand-to metal charge transfer (LMCT), metal-to-ligand charge-transfer (MLCT), metal-metal-to-ligand charge-transfer (MMLCT), ligandto-metal-metal charge transfer (LMMCT) and metal-toligand-ligand charge-transfer (MLLCT) states.
Owing to these outstanding photophysical properties associated with the above transitions, a variety of luminescence probes based on heavy metal complexes have been developed for the detection of amino acids in recent years. Several excellent reviews appeared earlier to focus on this topic as part of their works ${ }^{16-18}$. In light of this important field, the aim of this review is to highlight the recent development of heavy metal complexes as sensors for the detection of thiol containing amino acids. The complexation of heavy metal ions with various organic motifs and their photophysical properties will be briefly addressed. Subsequently, the application of these sensors for the detection and imaging of biothiols will be discussed, and their future prospects will be finally outlined.

\section{Phosphorogenic sensing of biothiols by heavy metal complexes}

For this purpose, several strategies have been developed over the last decade to sense thiol containing amino acids selectively using phosphorogenic heavy metal complexes such as $\operatorname{Re}(\mathrm{I}), \operatorname{Ru}(\mathrm{II}), \operatorname{Ir}(\mathrm{III})$, and $\mathrm{Pt}(\mathrm{II})$ complexes. The incorporation of thiol-recognition moieties, such as maleimide, aldehyde groups, sulfonate ester, azo linker and disulfide bond into the metal complexes allows to design a variety of thiol responsive luminescent probes. Maleimide containing probes undergo specific coupling with thiols leads to cyclization reaction that would display luminescence responsive behavior. In the case of aldehyde, it readily reacts with cysteine (Cys) or homocysteine (Hcys) to generate thiazinane or thiazolidine moiety, producing the emission signal changes. As arene sulfonate ester or arene sulfonamide is an electron withdrawing group, it quenches the emission intensity of coupled probes via an intramolecular photoinduced electron transfer (PET) process. Upon the cleavage of sulfonate or sulfonamide group by thiols, PET would be inhibited so that the emission of the metal complexes will be switched on. Another strategy is to employ 1,4 -addition of thiols to $\alpha, \beta$-unsaturated ketones of probes that would disrupt the $\pi$-conjugation of metal complex, generating a remarkable enhancement in emission intensity. The introduction of azo linker also quenches the emission intensity of probes Via an intramolecular PET process but the luminescence "switching-on" 
of probes would take place Via inhibiting the PET process by the thiol-mediated reduction of azo group.

\section{RESULTS AND DISCUSSION}

Depending on the nature of the coordinating ligands and metal centers, binding of the thiols at the recognition site would influence their luminescence behaviors to generate the emission signal changes. Some of the recent developments are discussed below.

\section{$\operatorname{Re}(\mathrm{I})$ complexes}

Using thiol-maleimide bioconjugate reaction strategy, Lo and coworkers prepared a series of maleimide containing rhenium(I) complexes, 1-6 $\left[\mathrm{Re}(\right.$ phen $)(\mathrm{CO})_{3}($ py-3mal $\left.)\right]\left(\mathrm{CF}_{3} \mathrm{SO}_{3}\right)$ (1), $\left[\operatorname{Re}\left(2,9-\mathrm{Me}_{2}-\right.\right.$ phen $)(\mathrm{CO})_{3}($ py-3-mal) $]\left(\mathrm{CF}_{3} \mathrm{SO}_{3}\right)$ (2), $\left[\operatorname{Re}\left(3,4,7,8-\mathrm{Me}_{4}\right.\right.$-phen $\left.)(\mathrm{CO})_{3}(\mathrm{py}-3 \mathrm{mal})\right]$ $\left(\mathrm{CF}_{3} \mathrm{SO}_{3}\right)(3),\left[\mathrm{Re}\left(4,7-\mathrm{Ph}_{2}-\right.\right.$ phen $)(\mathrm{CO})_{3}($ py-3-mal) $]$ $\left(\mathrm{CF}_{3} \mathrm{SO}_{3}\right)(4),\left[\mathrm{Re}\left(2,9-\mathrm{Me}_{2}-4,7-\mathrm{Ph}_{2}\right.\right.$-phen) $(\mathrm{CO})_{3}$ (py3-mal)] $\left(\mathrm{CF}_{3} \mathrm{SO}_{3}\right)(5)$, and $\left[\mathrm{Re}(\mathrm{biq})(\mathrm{CO})_{3}\right.$ (py-3$\mathrm{mal})]\left(\mathrm{CF}_{3} \mathrm{SO}_{3}\right)(6)(\text { Scheme } 1)^{19}$. The chemical composition of these complexes was analyzed by NMR, positive-ion ESI-MS, IR and elemental analyses.

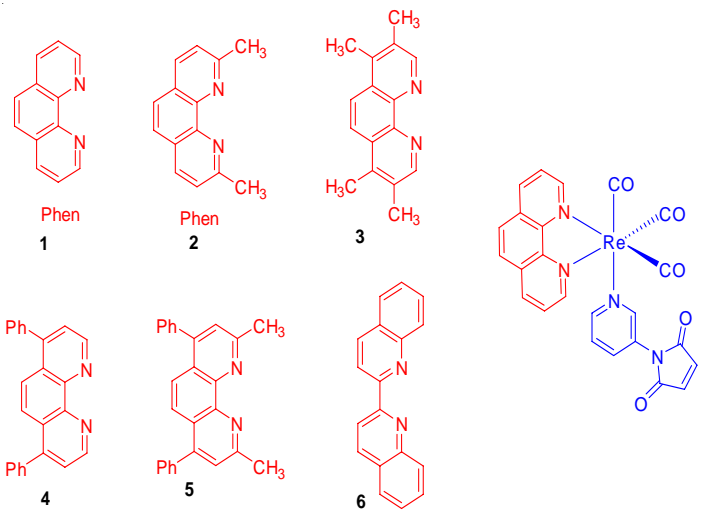

Scheme 1. Chemical structure of $\operatorname{Re}(\mathrm{I})$ complexes 1-6
UV-Vis absorption spectra of $1-3$ in $\mathrm{CH}_{2} \mathrm{Cl}_{2}$ showed intense absorption bands at 250-296 nm and a shoulder at 324-364 $\mathrm{nm}$ that are assigned to intraligand (IL) and metal-to-ligand charge-transfer ('MLCT) transitions, respectively. On the other hand, complexes 4-6 showed these transitions at 332382 and $374-408 \mathrm{~nm}$, respectively, because of increasing $\pi$-conjugation effect of coordinated ligands. Upon excitation at > $350 \mathrm{~nm}$, these complexes emitted ${ }^{3} \mathrm{MLCT}$ at 514-632 nm in $\mathrm{CH}_{2} \mathrm{Cl}_{2}$ with a lifetime of 0.10 to $7.42 \mathrm{~ms}$. Utilization of these complexes as site-specific labels for biological sulfhydryl species led to generate long-lived ${ }^{3} \mathrm{MLCT}$ emissions. For example, thiolated M13 sequencing primer M13-R [5'-HS( $\left(\mathrm{CH}_{2}\right)_{6}$-AACAGCTATGACCATG-3'], glutathione (GSH), bovine serum albumin (BSA) and human serum albumin (HSA) labeled with 1 showed a typical ${ }^{3} \mathrm{MLCT}\left[\mathrm{d} p(\mathrm{Re}) \rightarrow \pi^{*}(\right.$ phen $\left.)\right]$ character. The emission of the bioconjugate 1-GSH was efficiently quenched by oxygen whereas the complex 1 coupled to BSA, and HSA was shielded in the interior away from surrounding exposure, and hence, there emission were less quenched. The authors designed maleimide containing complex 1 to react with sulfhydryl biomolecules specifically and generate its thioether derivative (Scheme 2). In another study, a modified rhenium(I) complex $\left[\mathrm{Re}(\mathrm{bpy})(\mathrm{CO})_{3}\left(\mathrm{py}-\mathrm{CH}_{2} \mathrm{Cl}\right)\right]^{+}(7)$ was used to assess intracellular mitochondria of human breast adenocarcinoma cells ${ }^{20}$.

\section{Ruthenium(II) complexes}

Following a similar mechanism, a thiolreactive $\mathrm{Ru}(\mathrm{II})$ complex containing a maleimide group, bis(2,2'-bipyridine) (5-maleinimide-1,10phenanthroline) ruthenium (II)di(hexafluorophosphate) (8) was prepared (Scheme 3$)^{21}$.

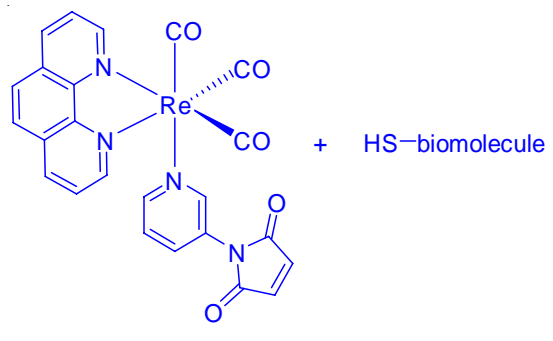

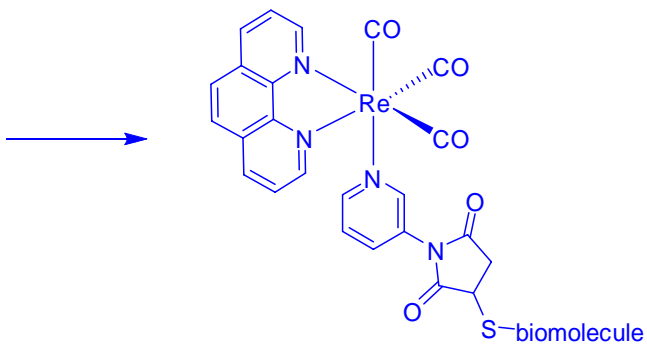

Scheme 2. Proposed reaction between the complex cation of 1 and the sulfhydryl group of a biomolecule 

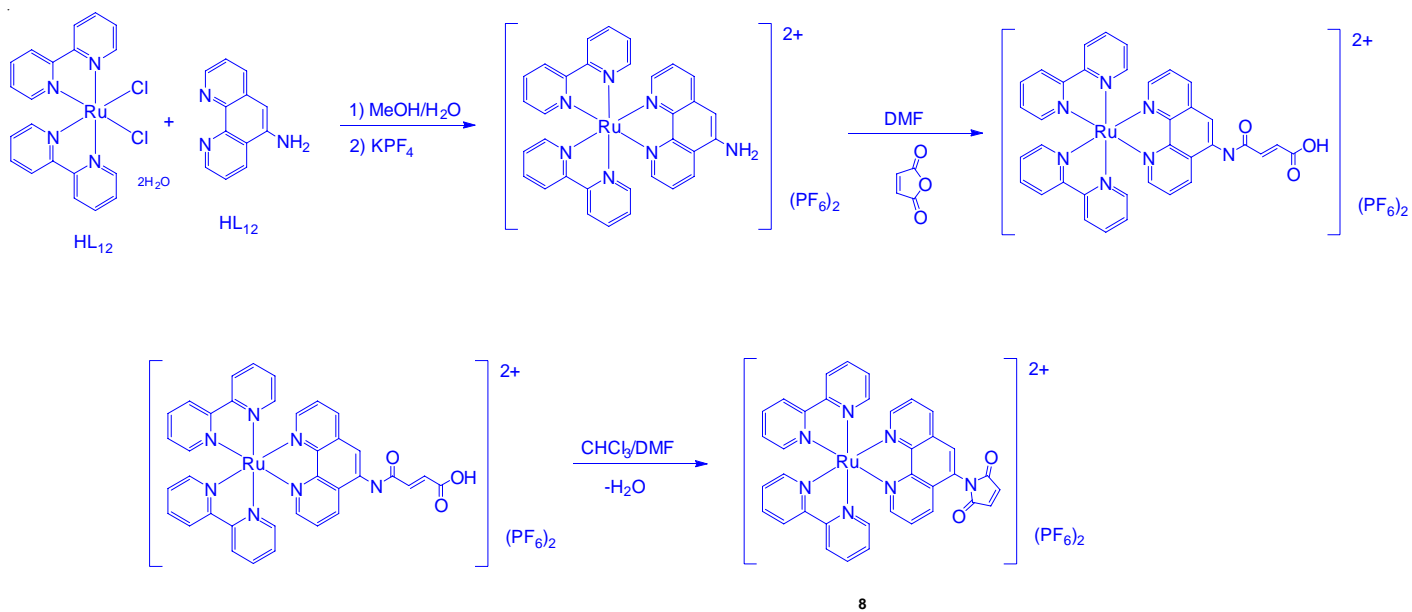

Scheme 3. Synthetic pathway for the thiol-reactive complex 8 starting from commercially available reagents

Complex 8 showed a MLCT absorption band at $454 \mathrm{~nm}$, and gave an emission at $606 \mathrm{~nm}$ with a quantum yield of $3.6 \%$. Emission analysis of 8 revealed that a significant emission was observed upon thiol conjugation. Furthermore, the labelling of HSA to 8 in combination with an acceptor cyanine dye and antibody permitted to study the influence of antibodies in a LET immunoassay at the nanomolar level.

One of the strategies to generate thiol-selective luminescent metal complexes is based on the cleavage of electron sink 2,4-dinitrobenzenesulfonyl motif (DNBS), which shows emission OFF-ON switching with good selectivity, from metal complexes in the presence of thiols. This process significantly results in phosphorescence enhancement. In 2010, Zhao group prepared two ruthenium(II) complexes [(1,10phenanthroline), ruthenium (5-amino-1,10phenanthroline $)]^{2+}\left(\mathrm{PF}_{6}\right)_{2}(9)$ and $[(1,10-$ phe nan th ro line) ${ }_{2}$ ruthenium(5-(2,4-dinitrobenzenesulfonamide)1,10-phenanthroline $\left.)]^{2+}\left(\mathrm{PF}_{6}\right)_{2}\right)_{2}(10)$ as shown in Scheme $4 .{ }^{22}$

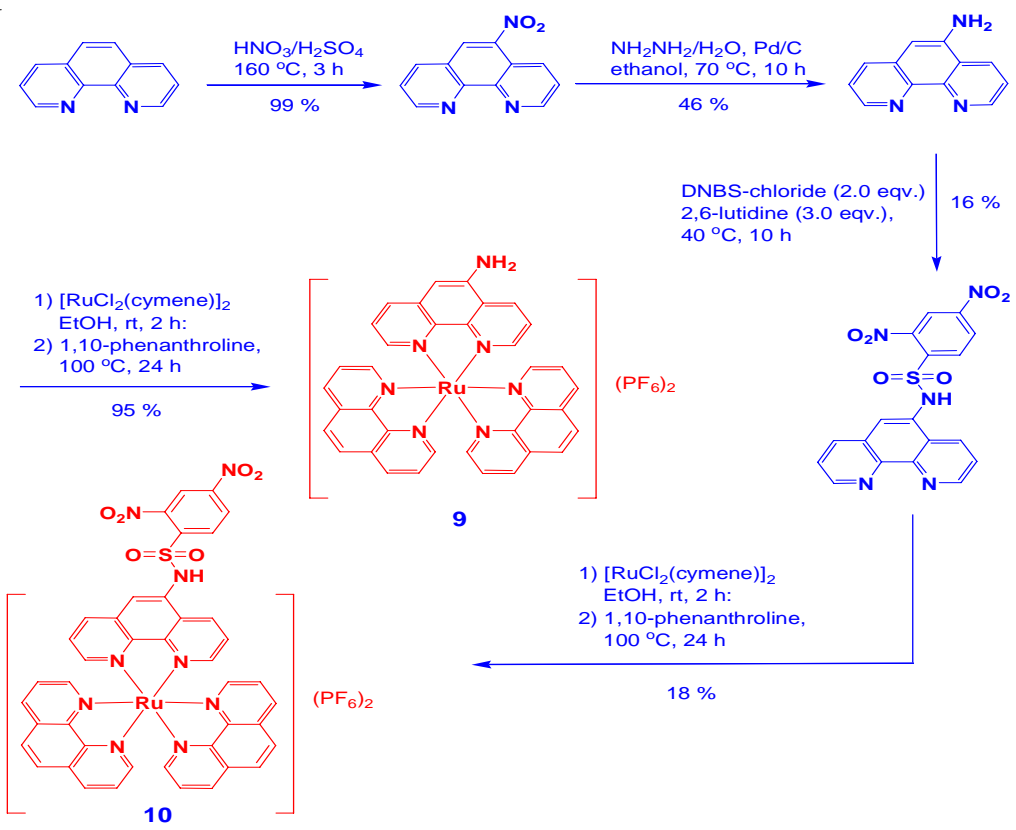

Scheme 4. Syntheses of complexes 9 and 10 
UV-Vis absorption spectra of compounds 9 and 10 showed a pi-pi ligand centered transition below at $300 \mathrm{~nm}$ and a MLCT band at 400-500 $\mathrm{nm}$. Upon excitation, complex 9 showed a ${ }^{3} \mathrm{MLCT}$ red emission at $600 \mathrm{~nm}$ with a long lifetime of is where as complex 10 displayed no emission owing to the quenching of MLCT band via the photoinduced electron transfer (PET) from electron rich Ru center to electron deficient DNBS moiety. In the presence

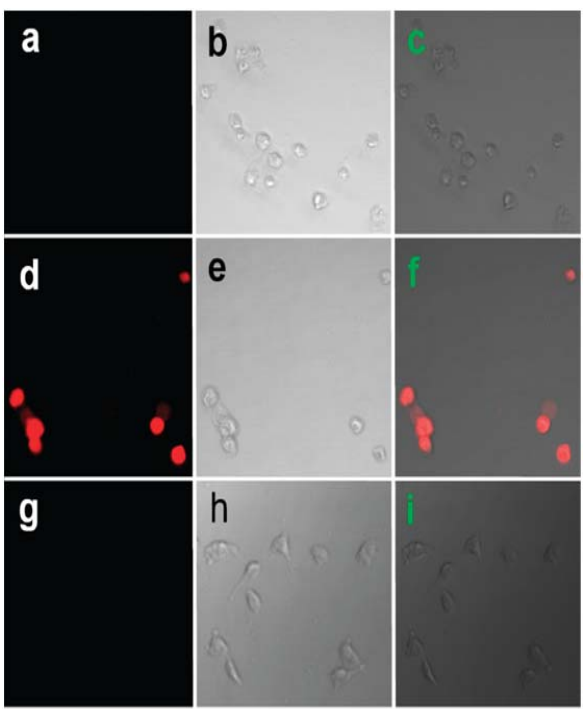

Fig. 1. Luminescence images of $\mathrm{NCl}-\mathrm{H} 446$ cells. (a) Images of cell. (d) Images of cells incubated with probe $10(30 \mu \mathrm{M})$ for $8 \mathrm{~h}$ at $37^{\circ} \mathrm{C}$. (g) Images of cells pretreated with $\mathrm{N}$-methylmaleimide $(0.5 \mathrm{mM})$ for $1 \mathrm{~h}$ at $37^{\circ} \mathrm{C}$ and then incubated with probe $10(30 \mathrm{iM})$ for $8 \mathrm{~h}$ at $37{ }^{\circ} \mathrm{C}$. (b, e, h) Bright field images corresponding to images a, d, g. (c) Overlay of images $a$ and $b$. (f) Overlay of images $d$ and e. (i) Overlay of images $g$ and $h$. Reproduced with permission from ref. 22. Copyright (2010) American Chemical Society

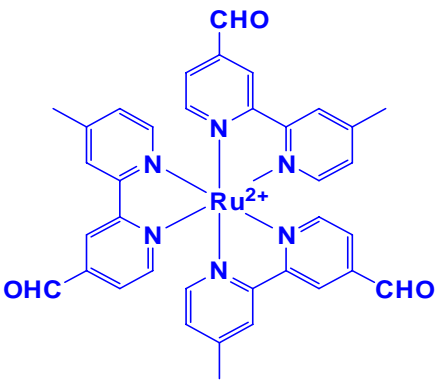

luminescence turn-off of thiols, cleavage of DNBS induced the increase in the emission intensity of 10 , as high as 90 -fold. Furthermore, compound 10 showed only a selective sensing towards thiol groups. The sensing mechanism of 10 with thiols was proposed and supported by DFT calculations. Cellular studies revealed that upon excitation compound 10 , showing red emission, was specific towards intracellular thiols among other analytes (Fig. 1). The authors believed that this work was the first report, showing the emission OFF-ON switch effect for the selective detection of thiol using ruthenium complex.

Ruthenium(II) complexes display outstanding photochemical and photophysical properties have been utilized as luminescence probes for the specific detection of biomolecules. In 2010, Yuan and coworkers prepared a tris(4-methyl-2,2'bipyridyl-4'-carboxaldehyde) ruthenium(II) hexafluorophosphate, $\left[\mathrm{Ru}(\mathrm{CHO}-\mathrm{bpy})_{3}\right]\left(\mathrm{PF}_{6}\right)_{2}(11)$ complex by refluxing a mixture of $\mathrm{CHO}$-bpy and $\mathrm{RuCl} \cdot 3 \mathrm{H}_{2} \mathrm{O}$ in $\mathrm{EtOH} / \mathrm{H}_{2} \mathrm{O}$ under inert atmosphere and employed as a probe for sensing of cysteine (Cys) and homocysteine (Hcys) (Scheme 5) ${ }^{23}$.

UV-Vis spectrum of 11 displayed two strong absorption bands at 300 and $485 \mathrm{~nm}$, which are attributed to the ligand localized $\pi-\pi^{*}$ and metal-toligand charge transfer (MLCT) transitions, respectively. Interestingly, addition of Cys and Hcys into a solution of 11 induced a blue-shifted absorption response of 11 from 485 to $465 \mathrm{~nm}$ and 300 to $290 \mathrm{~nm}$ with a color change from orange to yellow. In this methodology, compound 11

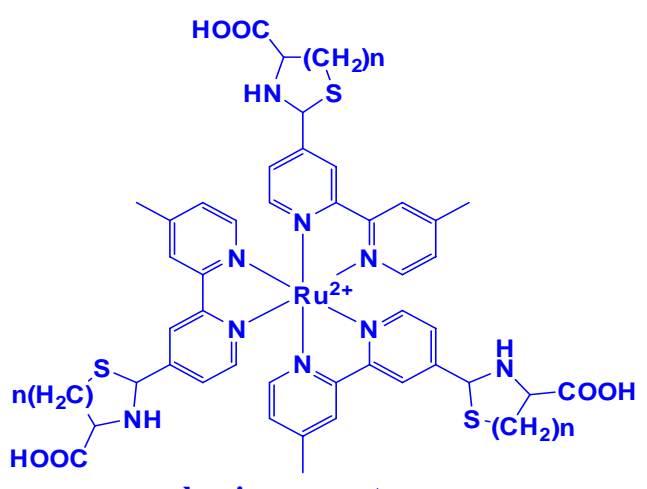

luminescence turn-on

11

Scheme 5. Luminescence response reaction of 11 towards Cys/Hcys 
contained aldehyde groups that function not only to quench the luminescence behavior of 11 , and hence it is non-emissive, but also recognize specific amino acids. Addition of Cys and Hcys resulted in significant luminescence enhancement and a blueshifted emission from 720 to $635 \mathrm{~nm}$ with a detection limits of 1.41 and $1.19 \mathrm{mM}$, respectively (Fig. 2). Based on the absorption and emission studies, it

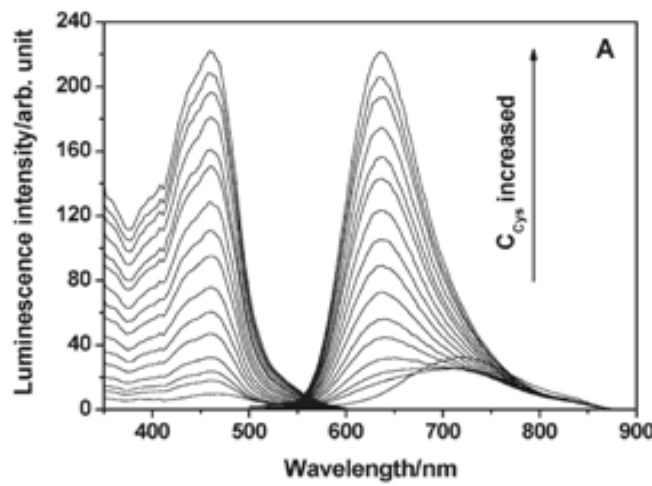

Fig. 2. Excitation and emission spectra of $11(10 \mu \mathrm{M})$ in the presence of different concentrations of Cys (A) and Hcys (B). The concentrations of Cys and Hcys are 50, 100, 150, 200, 250, 300, 400, 500, 600, 750, 900, 1200, 1500, 2100, and 3000 iM, respectively. Reproduced with permission from ref. 23. Copyright (2010) American Chemical Society

In another work using the similar strategy, a series of ruthenium(II) complexes (12-15) containing mono- or di-substituted aldehyde groups in one of the bpy ligands have been synthesized for the selective recognition of Hcys and $\mathrm{Cys}^{24}$. Compounds 12-15 (Fig. 3) were prepared by

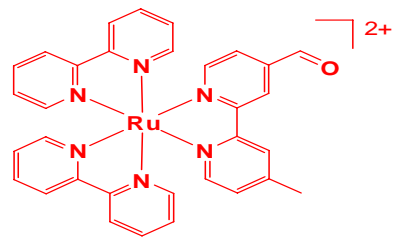

$\left[\operatorname{Ru}(\mathrm{bpy})_{2}(\mathrm{~L} 1)\right]^{2+} \quad(12)$

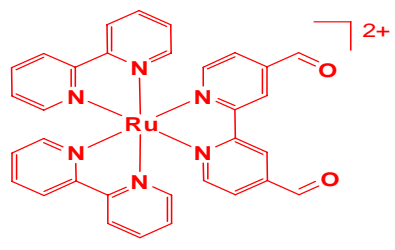

$\left[\operatorname{Ru}(\mathbf{b p y})_{2}(\mathbf{L} 2)\right]^{2+}$

(14)

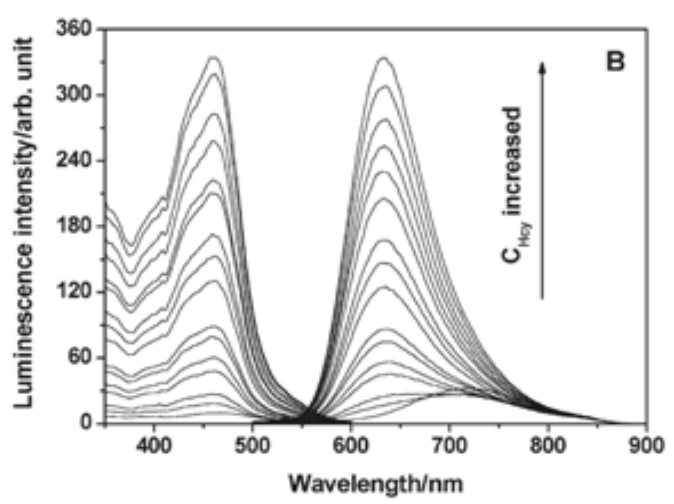

can be attributed by the formation of corresponding thiazolidine and thiazinane derivatives because of the degradation of aldehyde groups in 11 . Furthermore, this compound was highly selective for Cys/Hcys over other biomolecules such as other amino acids, DNA and proteins. This result suggests that luminescence change of 11 depends on the nature of the binding interaction between the aldehyde groups and the Cys/Hcys motifs (Scheme 5).

refluxing the reaction mixture of cis- $\mathrm{Ru}(\mathrm{bpy})_{2}$ $\mathrm{Cl}_{2} \cdot \mathrm{xH}_{2} \mathrm{O}$ or cis- $\mathrm{Ru}(\mathrm{dmb})_{2} \mathrm{Cl}_{2} \cdot \mathrm{xH}_{2} \mathrm{O}$ and 4-methyl2,2-bipyridine-4-carboxaldehyde (L1) and 4, 4-diformyl-2,2-bipyridine (L2) in ethanol under $\mathrm{N}_{2}$ atmosphere. These compounds were characterized NMR, MS-FAB and elemental analyses.
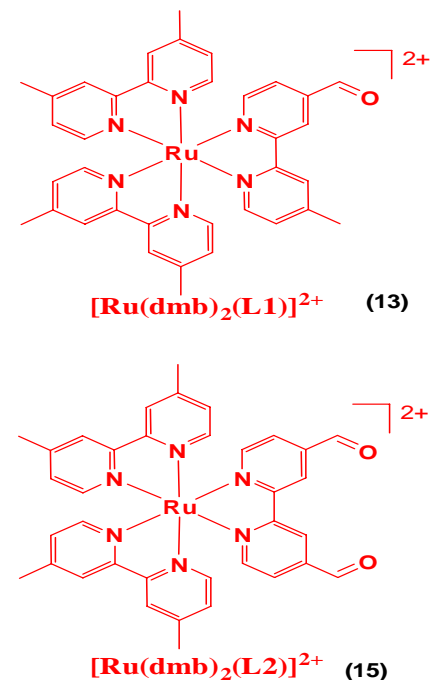

Fig. 3. Structures of the synthesized ruthenium(II) complexes 12-15 
The electronic absorption spectra of 12-15 exhibited an intense high-energy absorption bands at 276-308 $\mathrm{nm}$, and a weak low-energy bands at $416-492 \mathrm{~nm}$, corresponding to their intraligand (IL) and metal-to-ligand charge transfer $\left(\mathrm{MLCT}, \mathrm{d} \pi(\mathrm{Ru}) \rightarrow \pi^{*}(\right.$ ligand)) transitions, respectively. These complexes showed a weak triplet MLCT emission at $605-617 \mathrm{~nm}$ at room temperature because electron-withdrawing aldehyde groups quenched the MLCT emission of 12-15. Upon the addition of Hcys, the intensity of 15 at $492 \mathrm{~nm}$ decreased followed by the appearance of a new band at $461 \mathrm{~nm}$ with a blue-shift of $31 \mathrm{~nm}$ and two isosbestic points at 431 and $482 \mathrm{~nm}$. Other absorption bands displayed a smaller or no changes with isosbestic points at 304, 328 and 366 $\mathrm{nm}$. This result demonstrated that more aldehyde groups present in metal complexes would provide a larger spectral changes while interacting with Hcys or Cys, indicating their key role in the specific recognition studies. Addition of Hcys to compounds 12 and 13 caused a remarkable increase in luminescence intensity by 1.6 - and 1.9-fold with the detection limit of 4 and $15 \mathrm{mM}$, respectively, while a maximum increase of 8.5- and 10.1-fold with the detection limit of 2 and $13 \mathrm{mM}$, respectively, in the emission enhancement of the 14 and 15 was registered. On the other hand, a maximum of 1.3-, 3.5-, 1.6- and 4.5-fold with the detection limit of 5, 2, 4 and $1 \mathrm{mM}$, respectively, emission enhancement of $12-15$ was recorded at saturation in the presence of Cys. Compared with 12 and 13, compounds 14 and 15 showed a high affinity towards Cys and Hcys because of the presence of two aldehyde groups, giving a strong enhancement of the emission intensity. This is presumably due to the formation of thiazinane. Therefore, compounds 1215 were highly selective for Cys and Hcys over other amino acids as only Cys and Hcys could induce luminescence enhancement of these complexes.

Owing to the excellent photophysical properties of $\mathrm{Ru}(\mathrm{II})$ complexes, Yuan and coworkers ${ }^{25}$ prepared a $\mathrm{Ru}(\mathrm{II})$ complex, $\left[\mathrm{Ru}(\mathrm{bpy})_{2}\right.$ (DNBSO-bpy) $]\left(\mathrm{PF}_{6}\right)_{2}$ (bpy = 2,2'-bipyridine; DNBSO-bpy $=2,4$-dinitrobenzenesulfonate of 4-(4-hydroxyphenyl)-2,2'-bipyridine), (17) by the treatment of $\left[\mathrm{Ru}(\mathrm{bpy})_{2}(\mathrm{HP}-\mathrm{bpy})\right]\left(\mathrm{PF}_{6}\right)_{2}(16)^{26}$ with 2,4-dinitrobenzenesulfonyl chloride in dry $\mathrm{CH}_{2} \mathrm{Cl}_{2}$ in the presence of $\mathrm{NEt}_{3}$ at room temperature (Scheme 6) and used these two complexes 16 and 17 for the sensing of thiol containing amino acids by photoluminescence (PL) and electrochemiluminescence $(\mathrm{ECL})$ detection techniques.

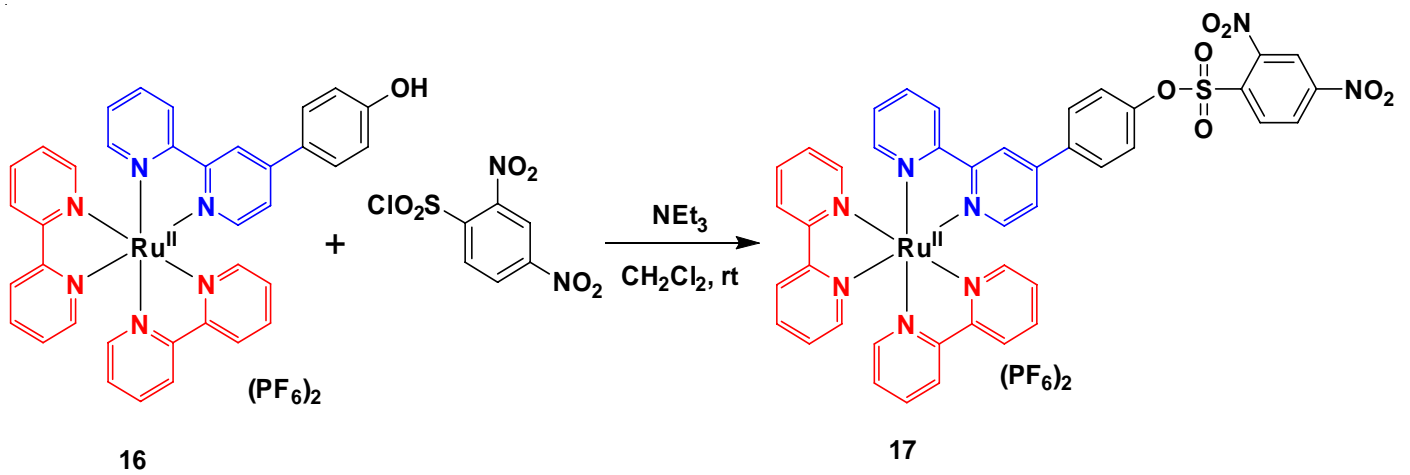

Scheme 6. Synthesis of Ru(II) complex 17 from 16

Complexes 16 and 17 displayed a MLCT band at $456 \mathrm{~nm}$ in HEPES buffer solution $(\mathrm{pH}=7.0)$. Treatment of 16 with 2,4-dinitrophenol did not show any observable changes in the luminescence spectrum of 16 . However, addition of thiol into 17 led to generation of quenching process, confirming that the intramolecular PET took place. Complex 17 showed a weak emission at $612 \mathrm{~nm}$, whereas complex 16 displayed a highly emission at $612 \mathrm{~nm}$ by 23 -fold to that of 17 . Upon the incremental addition of Cys or GSH, the excitation and emission intensity of 17 enormously increased with the detection limit of 20.1 and 19.8 $\mathrm{nM}$, respectively, in a 1:1 binding stoichiometry. However, other amino acids did not trigger any changes in the emission of spectrum of 17 . These results demonstrated that compound 17 is highly selective for the detection of thiol amino acids (Scheme 7). 


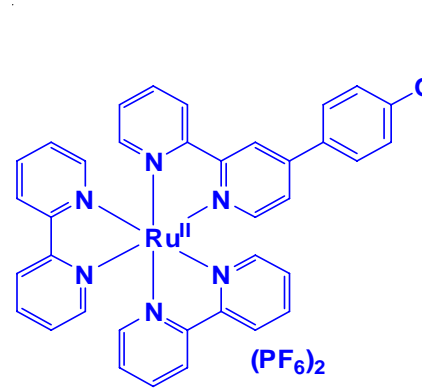

[Ru(bpy) ${ }_{2}$ (DNBSO-bpy) $]^{2+}$ weakly luminescent and ECL low active

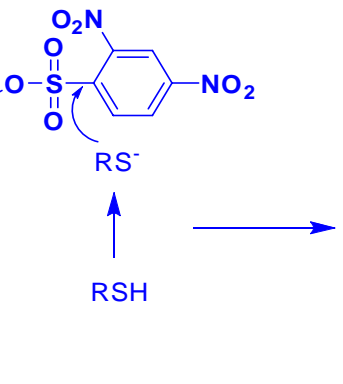<smiles>[R]Sc1ccc([N+](=O)[O-])cc1[N+](=O)[O-]</smiles>

17

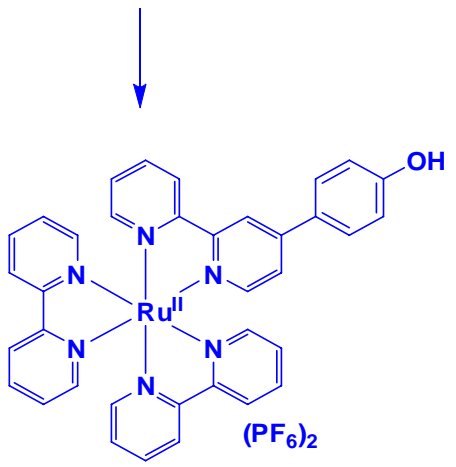

[Ru(bpy) ${ }_{2}$ (HP-bpy) $]^{2+}$ highly luminescent and ECL highly active

Scheme 7. Response reaction of 17 toward thiols

As evidenced by PL technique, the ECL intensity of 17 was also enormously increased with the detection limit of 86.5 and $56.3 \mathrm{nM}$, respectively, after the addition of Cys and GSH. At the same time, other amino acids and metal cations did not show any response towards the ECL intensity of 17 . Complex 17 treated HeLa cells displayed a red emission in the cytosol, indicating that this complex penetrated into the membrane and reacted with intracellular thiol. In the presence thiol scavenger $\mathrm{N}$-ethylmaleimide, no luminescence from complex
17 treated HeLa cells was found. However, when GSH was incubated with these non-luminescent cells, a strong red emission appeared from the cells, indicating the reaction of complex 17 with intracellular thiol groups. It was too difficult to detect imaging study by ECL technique because complex 17 reacted with thiols at the electrode surface.

$\mathrm{Ji}$ and coworkers prepared an azo containing $\mathrm{Ru}(\mathrm{II})$ complex (18, Fig. 4) by heating the reaction mixture of $\mathrm{Ru}(\mathrm{bpy})_{2} \mathrm{Cl}_{2}$ and azobpy ligand in $\mathrm{EtOH} / \mathrm{H}_{2} \mathrm{O}$ mixture ${ }^{27}$.

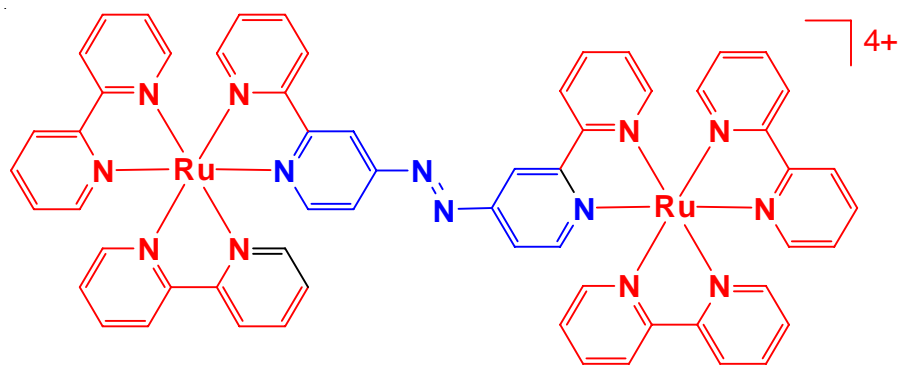

18

Fig. 4. Chemical structure of complex 
Addition of Cys, Hcys and GSH into the complex 18 resulted in the decrease of absorption intensity at $562 \mathrm{~nm}$ (MLCT ( $\pi \rightarrow$ azobpy $\pi^{\star}$ ) with a hyperchromic effect followed by increase of absorbance at $439 \mathrm{~nm}$ along with red shifted (attributed to MLCT $\left(\pi \rightarrow\right.$ bpy $\left.\pi^{*}\right)$ in a $2: 1$ stoichiometry ratio. During this reaction, the color of the solution from gray to yellow was appeared. This complex showed a weak emission at $605 \mathrm{~nm}$ because of quenching by azo linker Via an intramoleculear PET process. Upon the reduction of azo group by thiols, PET is inhibited so that the emission of the complex is switched on. Addition of Cys, Hcys and GSH enhanced the intensity of 18 by 35-, 36-, and 33-fold with the detection limit of $2.29 \times 10^{-7}, 2.27 \times 10^{-7}$, and $2.42 \times 10^{-7} \mathrm{M}$, in a $2: 1$ binding ratio, respectively. However, other amino acids including Cystine (oxidative form of Cys linked by disulfide) did not show any observable changes in the absorption and emission spectra of 18 . Under UV light, thiols can be differentiated from other amino acids by showing red color in the presence of 18 . This results indicated that complex 18 is selectively sensing thiol amino acids.

In another study, Yuan et al., designed a non-emissive complex that can be restored its emissive property upon interaction with thiol. Compound, [Ru(bpy $\left.)_{2}(\mathrm{DNS}-\mathrm{bpy})\right]\left(\mathrm{PF}_{6}\right)_{2}[\mathrm{bpy}=2,2$ 'bipyridine, DNS-bpy = 4-(2,4-dinitrophenylthio)-2,2'bipyridine] (19) was obtained by heating the reaction mixture of $\left[\mathrm{Ru}(\mathrm{bpy})_{2}(\mathrm{Cl}-\mathrm{bpy})\right]\left(\mathrm{PF}_{6}\right)_{2}$ (bpy $=2,22-$ bipyridine, $\mathrm{Cl}$-bpy $=4$-chloro-2,2-bipyridine) and 2,4dinitrothiophenol in the presence of $\mathrm{K}_{2} \mathrm{CO}_{3}$ and $\mathrm{KI}$ in anhydrous $\mathrm{CH}_{3} \mathrm{CN}$ under inert atmosphere (Scheme 8$)^{28}$. This compound was characterized by NMR, MS, and elemental analyses.

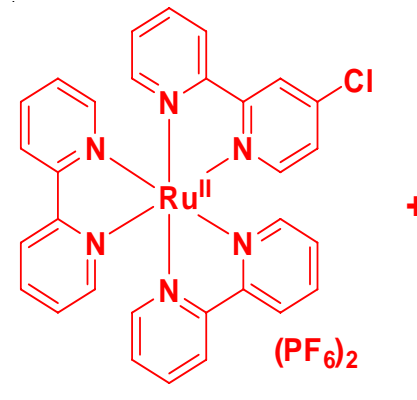

$\left[\mathrm{Ru}(\mathrm{bpy})_{2}(\mathrm{Cl}-\mathrm{bpy})\right]\left(\mathrm{PF}_{6}\right)_{2}$

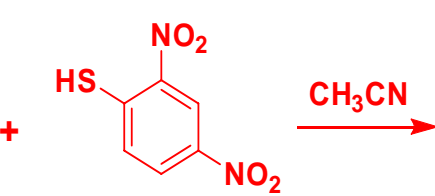<smiles></smiles>

$\left[R u(b p y)_{2}\left(D_{N S-b p y)}\right)\left(P_{6}\right)_{2}\right.$

Scheme 8. Reaction pathway for the synthesis of $\mathrm{Ru}(\mathrm{II})$ compound, 19

Absorption spectrum of 19 in the absence and presence of GSH, Cys or Hcys in ethanolHEPES buffer $(\mathrm{pH} 7.2)$ showed only a typical MLCT band (458 $\mathrm{nm}$ ). However, a significant enhancement at $330 \mathrm{~nm}$ in 19 was observed along with the formation of new absorption band related to 2,4-dinitrophenyl moiety, after the addition of GSH, Cys and Hcys. This result demonstrated that thiols cleaved 2,4-dinitrophenyl moiety from the complex 19 , which is in agreement with the previous report $^{26}$. In the absence of biothiols, complex 19 displayed a weak emission at $625 \mathrm{~nm}$ upon excitation at $458 \mathrm{~nm}$. Investigation of luminescence response of 19 towards biothiols showed that GSH cleaved DNBS moiety and induced the increase in the emission intensity of 19 , as high as 80 -fold with the detection limit of $1.0 \mu \mathrm{M}$, indicating its highly sensitive detection of biothiols (Fig. 5). In addition, the effect of $\mathrm{pH}$ on the emission response of 19 towards biothiols was also examined.

The electron withdrawing 2,4-dinitrophenyl moiety quenched the emission of 19 . However, thiols underwent $S_{N} A r$ substitution reaction and cleaved to eliminate 2,4-dinitrophenyl moiety from 19 , so that the MLCT emission of 19 can be restored (Scheme 9). 


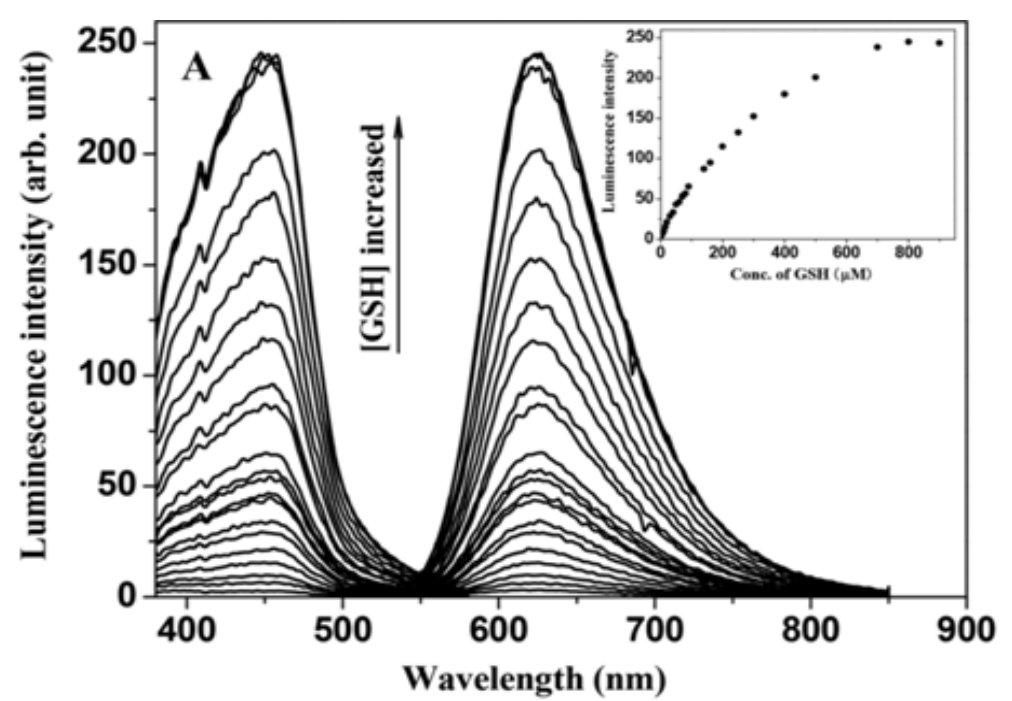

Fig. 5. Excitation and emission spectra of $19(10 \mathrm{iM})$ in the presence of different concentrations of GSH $(0,5,10,15,20,30,40,50,60,70,80,90$, $140,160,200,250,300,400,500,700,800,900 \mathrm{iM})$ in 1:4 ethanol-50 mM HEPES buffer of pH 7.2 at room temperature (the inset shows the emission intensity changes at $625 \mathrm{~nm}$ in the presence of different concentrations of

GSH). Reproduced with permission from ref. 28. Copyright (2014)

Royal Society of Chemistry

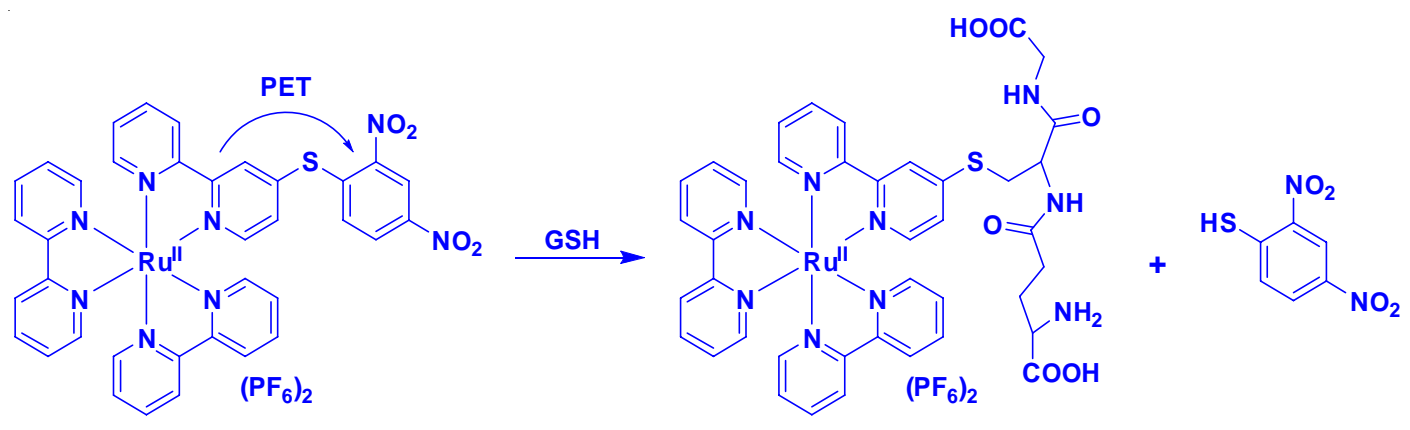

$\left[\mathrm{Ru}(\mathrm{bpy})_{2} \text { (DNS-bpy)](PF } 6\right)_{2}$

$\left[\mathrm{Ru}(\mathrm{bpy})_{2}(\mathrm{GSH}-\mathrm{bpy})\right]\left(\mathrm{PF}_{6}\right)_{2}$

\section{9}

Scheme 9. Structure of 19 and its luminescence response following reaction with GSH

Compared with GSH, both Cys and Hcys triggered a much lower luminescence enhancement in 19 because they attacked the carbon attached to the sulfur to form stable C-N bond. But GSH has no adjacent amino group, which is very difficult to lead intramolecular substitution. At the same time, other amino acids could not be able to induce the emission intensity of 19. Lastly, the emission imaging of biothiols in Daphnia magna animal study using compound 19 demonstrated its applicability towards biothiols specifically.

\section{Iridium(III) complexes}

In order to demonstrate the utility of metal complexes in protein staining, two cyclometalated iridium complexes, $\left[\operatorname{lr}(\mathrm{ppy})_{2}(\mathrm{solv})_{2}\right]^{+}(20 ; \mathrm{ppy}=2-$ phenylpyridine; solv $=\mathrm{H}_{2} \mathrm{O}$ or $\mathrm{CH}_{3} \mathrm{CN}$ ) and $\left[\operatorname{lr}(\mathrm{ppy})_{3}\right]$ (21) were chosen (Fig. 6). Treatment of $\left[\operatorname{lr}(\mathrm{ppy})_{2} \mathrm{Cl}\right]_{2}$ with AgOTf in the presence of $\mathrm{H}_{2} \mathrm{O}$ or $\mathrm{CH}_{3} \mathrm{CN}$ resulted in the formation of complex 20 whereas compound 21 is formed by dissolving the dimer $\left[\operatorname{lr}(\mathrm{ppy})_{2} \mathrm{Cl}\right]_{2}$ in $1 \mathrm{M} \mathrm{HCl}^{29}$. 


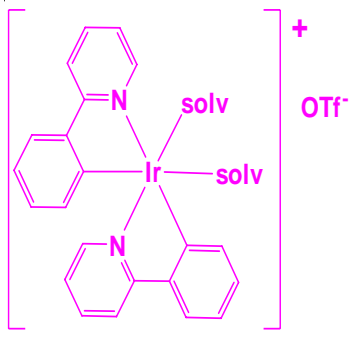

20

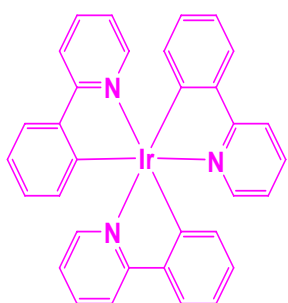

21

solv $=\mathrm{H}_{2} \mathrm{O}, \mathrm{CH}_{3} \mathrm{CN}$

Fig. 6. Structure of cyclometalated iridium complexes 20 and 21

Complex 20 showed a weak emission in phosphate buffered saline (PBS). However, the addition of histidine (His) induced the emission

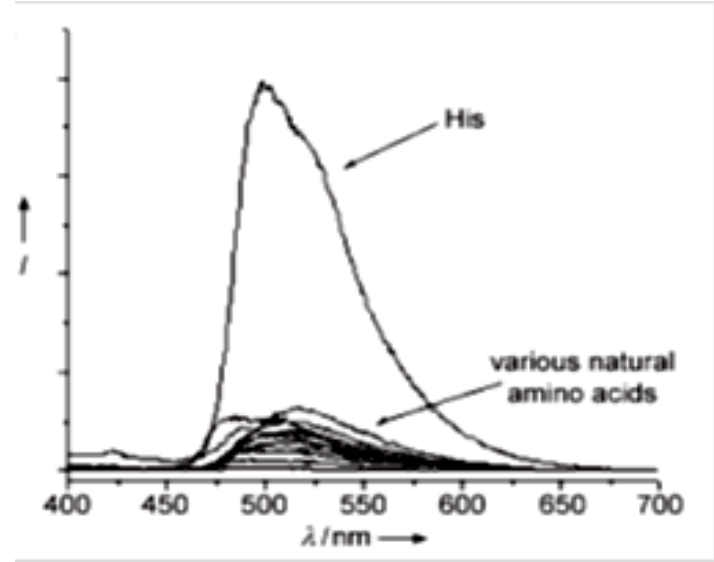

Fig. 7. Emission spectra of $20(50 \mathrm{~mm})$ in PBS buffer with His and various natural amino acids $(200 \mathrm{~mm})$ at $20{ }^{\circ} \mathrm{C}$. Reproduced with permission from ref. 29. Copyright (2008) John Wiley \& Sons

enhancement of 20. On the other hand, other amino acids responded with weak or no emission (Fig. 7). This result suggested that compound 20 was selectively sensing His, which was also confirmed by electrospray-ionization positive-ion mass spectrometry.

High abundance of histidine residues, such as bovine serum albumin (BSA) also induced the emission enhancement of 20. In contrast, compound 21 did not show any response in its emission intensity with BSA. Furthermore, the response of 20 to BSA was not affected by nonprotein substances such as inorganic salts, chelating agent EDTA, and detergents like SDS, Triton $\mathrm{X}-100$. As this complex 20 recognized histidine and histidine-rich proteins, it can be applied to the detection of proteins through Western blot and SDS-PAGE gel analyses.

By inspiring the strategy of 1,4-addition of thiols to $\alpha, \beta$-unsaturated ketones, Chen and coworkers $^{30}$ designed cyclometalated iridium(III) complex $\left[\operatorname{Ir}(\mathrm{ppy})_{2}(\mathrm{~L})\right]\left(\mathrm{PF}_{6}\right),(22)$, which was obtained by the treatment of functionalized 2,2'-bipyridine with $\mathrm{Ir}_{2}(\mathrm{ppy})_{4}(\mu-\mathrm{Cl})_{2}$ precursor in $\mathrm{CH}_{2} \mathrm{Cl}_{2}-\mathrm{CH}_{3} \mathrm{OH}$ mixture under reflux (Scheme 10), and studied the conversion of ${ }^{3} \mathrm{LLCT}$ to a mixed ${ }^{3} \mathrm{MLCT}$ and ${ }^{3} \mathrm{LLCT}$ state upon thiol detection. The 1,4-additive reaction of 22 with benzenethiol resulted in the formation of compound 23. These compounds were characterized by positive ion ESI-MS, NMR, elemental analyses, and X-ray crystallographic studies.

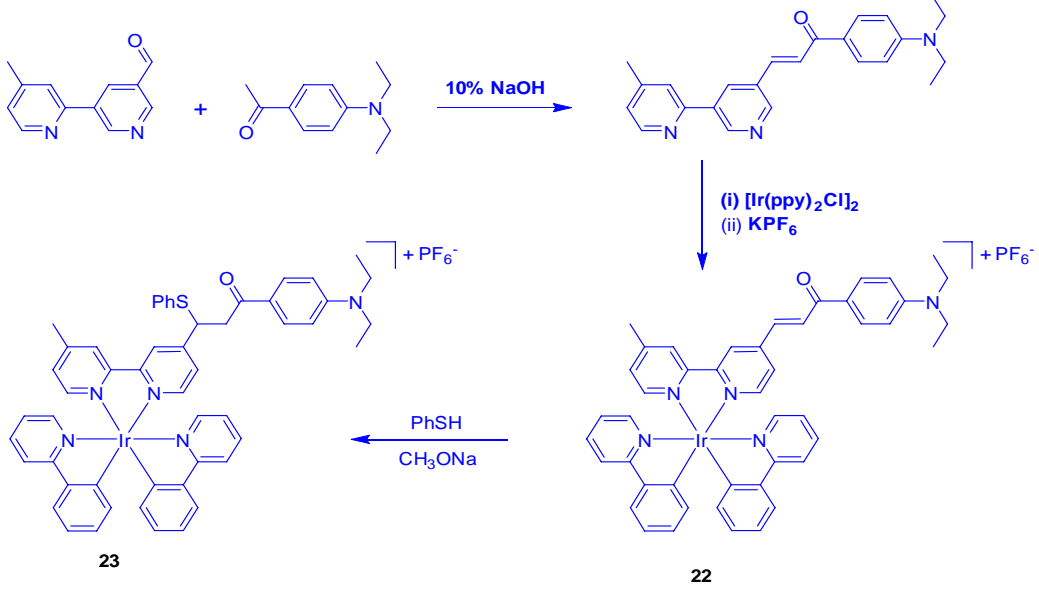

Scheme 10. Synthetic routes to 22 and 23 
Complex 22 displayed an ppy-, and functionalized bpy-based transition at 280-320 nm, and intraligand charge transfer (ILCT) transition mixed with $\left[5 \mathrm{~d}(\mathrm{Ir}) \rightarrow \pi^{\star}(\mathrm{L})\right] \mathrm{MLCT}$ and $\left[\pi(\mathrm{ppy}) \rightarrow \pi^{\star}(\mathrm{L})\right]$ LLCT transition at $450 \mathrm{~nm}$, which was supported by DFT calculations. Addition of Cys into a DMFHEPES buffer solution of 22 showed a decrease in the intensity at $450 \mathrm{~nm}$ followed by increase in the intensity at $350 \mathrm{~nm}$ with the isosbestic points at 325 $\mathrm{nm}$ and $372 \mathrm{~nm}$, indicating the formation of new species. Compound 22 showed a broad emission at $587 \mathrm{~nm}$ with a quantum yield of 0.013 and a lifetime of $109 \mathrm{~ns}$, which was originated from ${ }^{3}$ LCCT mixed with ${ }^{3}$ LLCT and ${ }^{3}$ MLCT states. The ${ }^{3}$ ILCT excited state deactivated effectively non-radiative process, and hence compound 22 was weakly emissive. Upon the addition of 80 equiv. of Cys or Hcys, the emission intensity of 22 at $587 \mathrm{~nm}$ showed a 20-, and 14-fold enhancement with increasing their lifetime of 358 and 127 ns, respectively (Fig. 8). Based on the observations from UV-Vis and emission studies, it was clear that the thioether moiety in the adduct 22-Cys/22-Hcys converted the emission from ${ }^{3} \mathrm{ILCT}$ excited state to a highly emissive ${ }^{3}\left[\pi(\text { ppy }) \rightarrow \pi^{*}(\mathrm{~L})\right]^{3} \mathrm{LLCT}$ and ${ }^{3}\left[5 \mathrm{~d}(\mathrm{Ir}) \rightarrow \pi^{*}(\mathrm{~L})\right]$ ${ }^{3} \mathrm{MLCT}$ states. Compound 23 showed an intense emission band at $587 \mathrm{~nm}$ with a lifetime of $131 \mathrm{~ns}$. The reactivity of 22 towards thiols was found in the order of $\mathrm{Cys}>\mathrm{Hcy}>\mathrm{GSH}$, indicating the importance

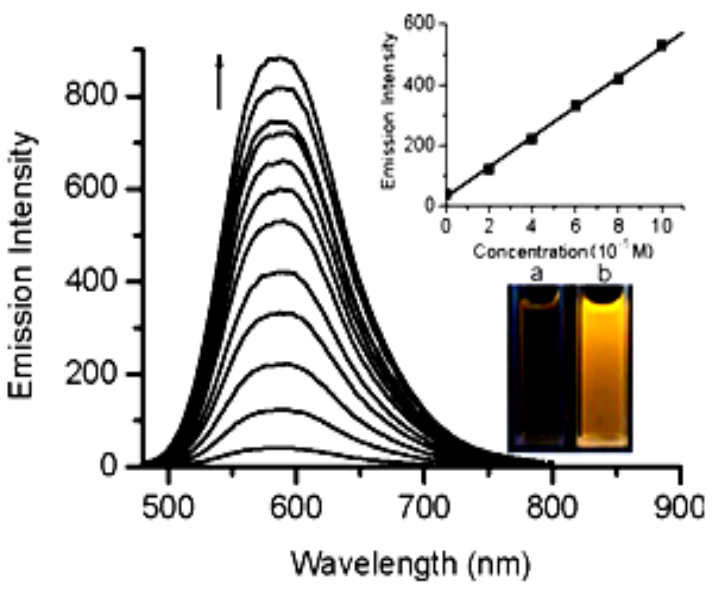

Fig. 8. Changes in emission spectra of complex 22 (20 $\mathrm{mM})$ in DMF-HEPES buffer solution $(50 \mathrm{mM}$, pH $7.2,4: 1, v / v)$ upon titration with Cys (0-80 equiv). The equilibration time is ca. $40 \mathrm{~min}$. Top inset: Plot of the emission intensity at $587 \mathrm{~nm}$ as a function of Cys concentration (0-10-4 M). Bottom inset: Luminescence images before (a) and after (b) addition of 80 equiv Cys. Reproduced with permission from ref. 30 . Copyright (2010) Royal Society of Chemistry of steric hindrance effect. The UV-vis and emission responses of 22 towards competitive amino acids showed no significant changes in their spectra except Cys. This result demonstrated that the sensing properties of 22 to Cys was selective, which was also confirmed by ESI-MS and NMR measurements. Furthermore, DFT studies supported a remarkable intensity enhancement by the conversion of ILCT transition in 22 to the MLCT/ LLCT states in 22-Cys when Cys interacted with a,b-unsaturated ketone in 22 .

Previously, Li and co-workers found a long response time for detecting cysteine (Cys) and homocysteine (Hcy) using two iridium(III) complexes, $\left[\operatorname{Ir}(\mathrm{pba})_{2}(\mathrm{acac})\right]$ and $\left[\operatorname{Ir}(\mathrm{pba})_{2}(\mathrm{bpy})\right]^{+}(\mathrm{pba}$ $=4-(2-$ pyridyl $)$ benzaldehyde, acac $=$ acetylacetonate, and bpy $=2,2^{\prime}$-bipyridine $)^{31,32}$. But, Che group developed a series of iridium(III) complexes (24 and 25a-25d) derivatized with a diarylazo quencher based on fluorescence resonance energy transfer (FRET) strategy (Scheme 11) that exhibits a short response time for sensing of these thiol containing amino acids $^{33}$.

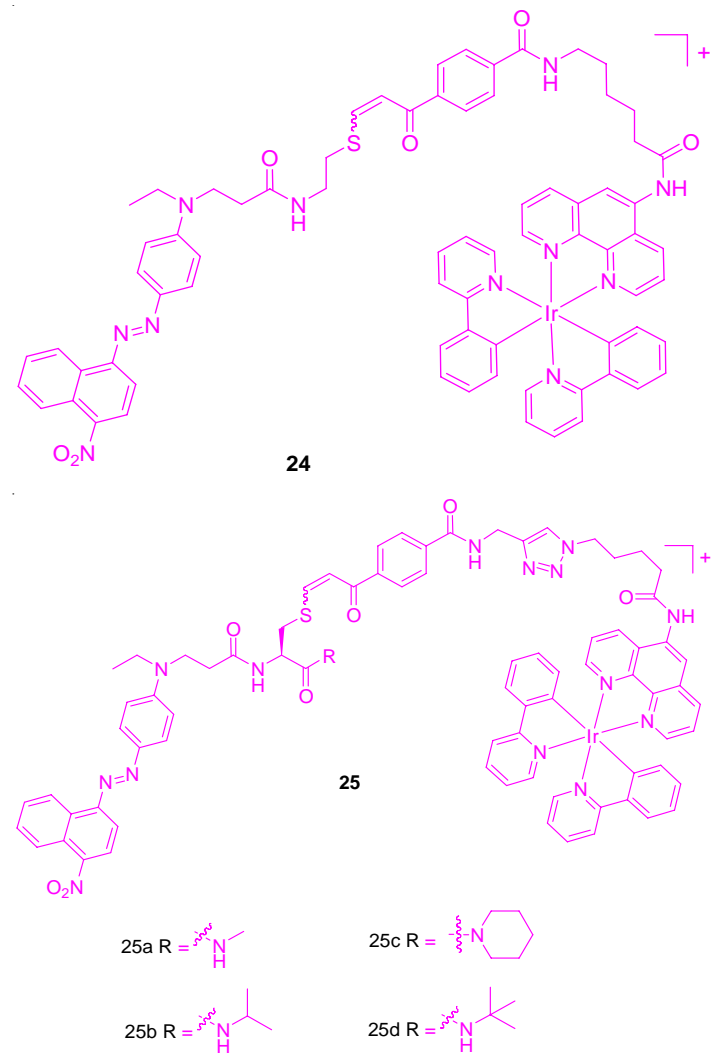

Scheme 11. Chemical structure of compounds 24 and 25a-25d 
Compound 24 was exhibited to be weakly emissive as the azo dye quenched the luminescence signal of $\mathrm{Ir}$ (III) chromophore. But, a maximal 46-fold emission enhancement of 24 at $590 \mathrm{~nm}$ was observed with the detection limit of $0.13 \mathrm{mM}$ in response to Hcy under optimal condition, while the emission of 24 was enhanced by 33-fold in the presence of Cyc. The increase in emission of 24 was attributed by the nucleophilic attack of Cys or Hcys at the vinyl sulfide linkage of 24 to displace azo quencher from the metal complex. Furthermore, this complex displayed significant selectivity for Cys, and Hcy over a panel of other amino acids including GSH (Fig. 9). As alkyl R group in compound 25 enhanced steric clouds around vinyl sulfide linkage, the smaller Hcys can easily cleave the azo dye from the $\operatorname{Ir}(\mathrm{III})$ chromophore, thus restoring the emission intensity of 25 . Due to bulky nature of thiolcontaining GSH, it was not able to hinder the nucleophilic attack against the vinyl sulfide linkage of 25 , and therefore, its response almost was lacking. Among the probes 24 and 25a-25d, the tert-butyl group in $25 \mathrm{~d}$ was able to distinguish between Hcys and Cys with a selectivity ratio of $5: 1$.

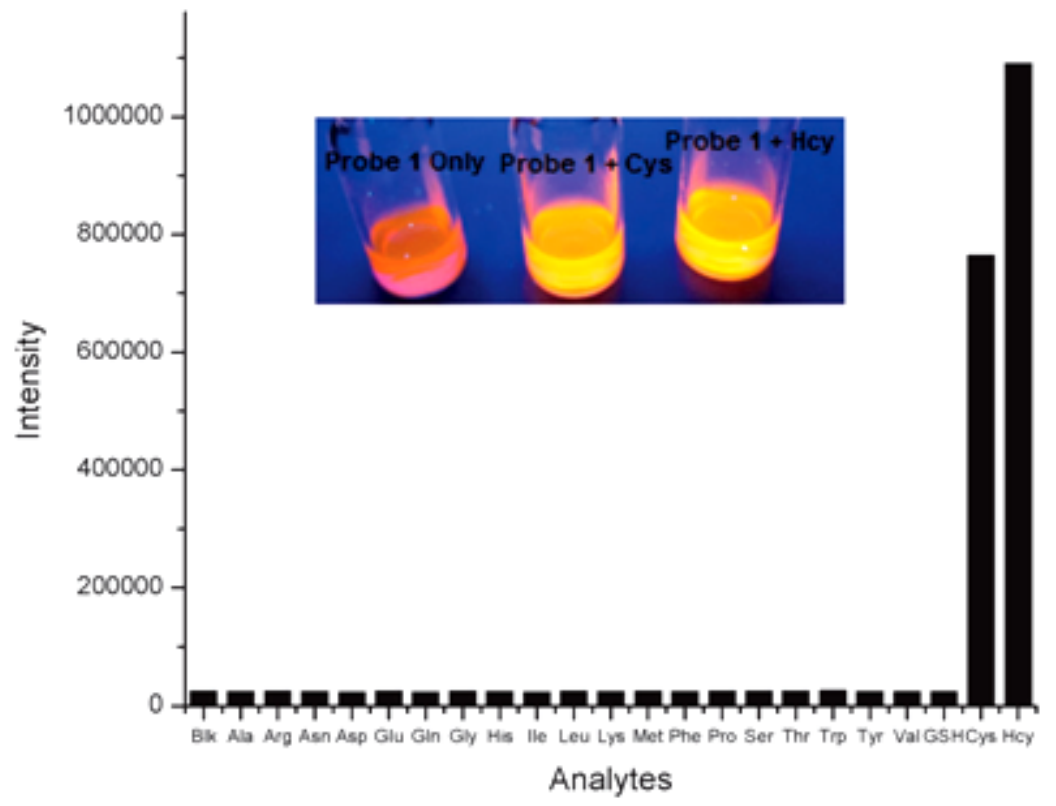

Fig. 9. Emission enhancement in the detection of different analytes by 24. Reproduced with permission from ref. 33. Copyright (2013)

Royal Society of Chemistry

In another study, Huang and coworkers ${ }^{34}$ demonstrated that quaternary amino group attached to the phenanthroline ligand in cyclometallated iridium(III) complexes $\left[\operatorname{Ir}\left(\mathrm{C}^{\wedge} \mathrm{N}\right)_{2}\right.$ pto] ${ }^{+} \mathrm{PF}_{6}-\left(26 \mathrm{a}-26 \mathrm{~d}, \mathrm{C}^{\wedge} \mathrm{N}=2\right.$-(2,4- difluorophenyl) pyridine (dfppy), 2-(4-(tert-butyl)phenyl)pyridine (t-buppy), 2-(thiophen-2-yl) quinoline) (thq), 4-(pyridin-2-yl)benzaldehyde (pba) and pto = the quaternization of the tertiary amino group containing 2-chloro-N-(1,10-phenanthrolin-5-yl) acetamide (cpa) ligand) showed a good water solubility and functioned as sensors for the selective detection of Cys and Hcys in an intracellular environment.

$\mathrm{Li}$ and coworkers $^{35}$ firstly demonstrated a new strategy for detecting the nuclei of living cells using non-emissive iridium complex as a reaction-based light-up imaging agent (Scheme 12). The cyclometalated iridium(III) solvent complex, $\left[\operatorname{lr}(\text { ppy })_{2}(\mathrm{DMSO})_{2}\right]+\mathrm{PF}_{6}-(27)$, was prepared by heating the reaction mixture of $\left[(p p y)_{2} \operatorname{Ir}(\mu-C l)_{2} \operatorname{Ir}\right.$ $\left.(\mathrm{ppy})_{2}\right]$, which was obtained upon the reaction of $\mathrm{IrCl}_{3} \cdot 3 \mathrm{H}_{2} \mathrm{O}$ with 2-phenylpyridine (ppy) under reflux, and DMSO solvent. UV-Vis absorption spectrum of 27 in HEPES buffer solution exhibited an intraligand $\left(\pi-\pi^{\star}\right)$ ppy transition at $250-325 \mathrm{~nm}$, and a mixed singlet and triplet metal-to-ligand charge-transfer ( ${ }^{1} \mathrm{MLCT}$ and ${ }^{3} \mathrm{MLCT}$ ) transition as a weak band at $330-470 \mathrm{~nm}$. Compound 27 is non-luminescent both in solution and solid states. 


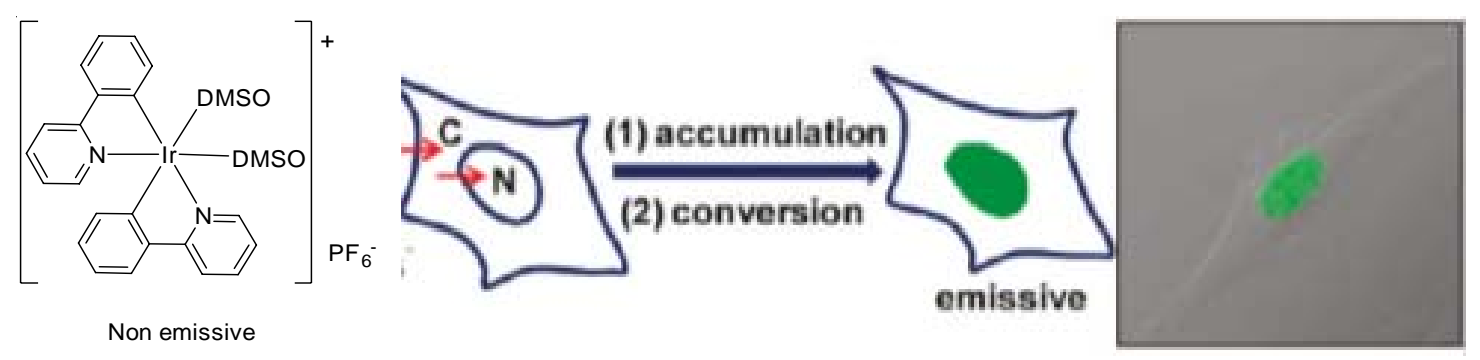

27

Scheme 12. Chemical structure and the proposed mechanism of nuclear staining with nonemissive iridium(III) complex 27. The characters 'C' and ' $N$ ' denote cytoplasm and nucleus, respectively. Reproduced with permission from ref. 35. Copyright (2011) American Chemical Society.

Cellular uptake studies of non-emissive compound 27 showed a bright emission in the region of nuclei upon incubating with HeLa, KB, FLS, and MSC cells under excitation at $488 \mathrm{~nm}$. In addition, its emission was perfectly colocalized with the nuclear counterstain Hoechst 33258, indicating the characteristic of its imaging probe without the assistance of any membrane-permeable agent (Fig. 10). It was also found that complex 27 possessed a low toxic effect towards cellular nuclei.

The luminescence signal of 27 is enormously induced at different enhancements when it interacted with histidine and histidine-rich proteins. It is proposed that this complex 27 was able to permeate the membranes of living cells via energy-dependent entry pathway and convert into emissive adduct after accumulating the nuclei of living cells (Scheme 12). This complex showed

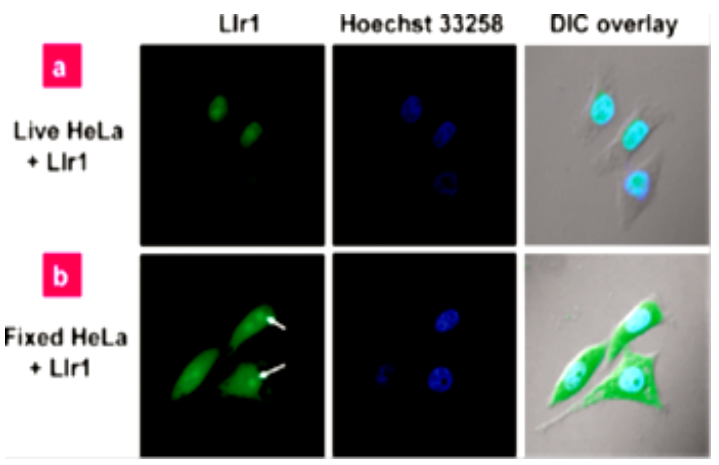

Fig. 10. Confocal luminescence images of (a) living HeLa cells incubated with $10 \mu \mathrm{M} 27$ in DMSO/PBS (pH 7.4, 1:99, v/v) for $10 \mathrm{~min}$ at $37^{\circ} \mathrm{C}$ and then further incubated with Hoechst 33258, and (b) fixed HeLa cells stained with 27 and Hoechst 33258 under the same conditions. Arrows point to the nucleolus of HeLa cells. Reproduced with permission from ref. 35. Copyright (2011) American Chemical Society several advantages include short duration for cell staining, excitation using visible light, high signal ratio between the cytoplasm and the nucleus, low cytotoxicity, and no conjugation required in association with a cell-penetrating molecular transporter, to light up nuclear staining of living cells in biomedical research.

Due to the advantageous photophysical properties of iridium(III) complex, Huang et al., ${ }^{36}$ prepared probe 29 by the reaction of Ir (III) complex 28 , which was obtained through complexation of $\left[\operatorname{Ir}\left(\mathrm{C}^{\wedge} \mathrm{N}\right)_{2} \mathrm{Cl}\right]_{2}\left(\mathrm{C}^{\wedge} \mathrm{N}=2\right.$-(thiophen-2-yl)quinoline) with 3-hydroxypicolinic acid, and 2,4-dinitrobenzene-1sulfonyl chloride as shown in Scheme 13. Its chemical structure was confirmed by NMR and MALDI-TOF mass spectroscopies.

Complex 29 showed two intense absorption bands at 289 and $335 \mathrm{~nm}$ and a moderate band at $400-500 \mathrm{~nm}$ that are corresponding to ligand-centered and mixed singlet and triplet metal-to-ligand charge-transfer in associated with ligand-to-ligand charge-transfer transitions, respectively. As DNBS moiety quenched the emission of 29 via PET pathway, probe 29 was non-emissive, which was demonstrated clearly by DFT calculation. Treatment of Cys with probe 29 resulted in the increase in absorbance of 29 at 250-550 nm, showing the interaction of Cys towards probe 29. In the case of emission properties of 29 , upon the addition of Cys, a significant emission is observed at $603 \mathrm{~nm}$, which is similar to that of emission band of compound 28. The "OFF-ON" luminescence sensing mechanism was proposed by the fact that cleavage of sulfonate ester of probe 29 by Cys afforded red light emitted complex 28, which was clearly demonstrated by ${ }^{1} \mathrm{H}$ NMR, 
time-resolved and MALDI-TOF mass spectral techniques. Other amino acids did not show any noticeable changes in the emission spectra of 29. However, bovine serum albumin (BSA) triggered to increase the emission intensity of 29 slightly, but not as strong as those of Cys or Hcys, indicating the difference in their charge and structural motif characters (Figure. 11).
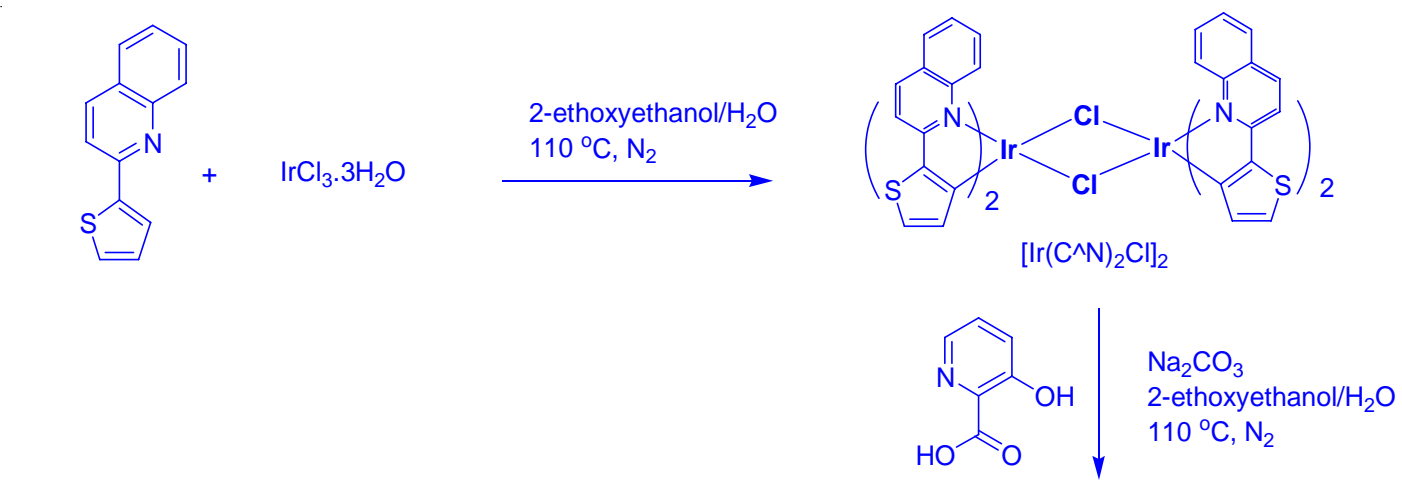

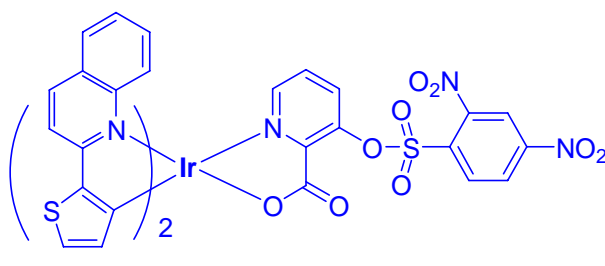

29

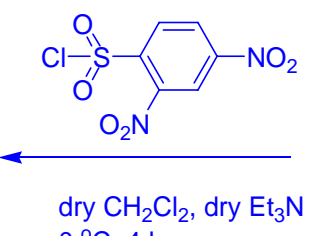

$0{ }^{\circ} \mathrm{C}, 4 \mathrm{~h}$

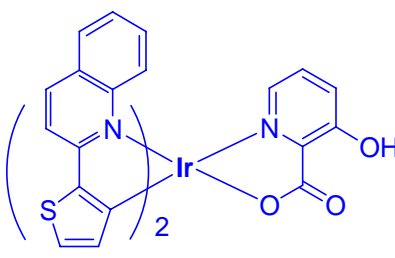

28

Scheme 13. Synthesis of complex 28 and probe 29

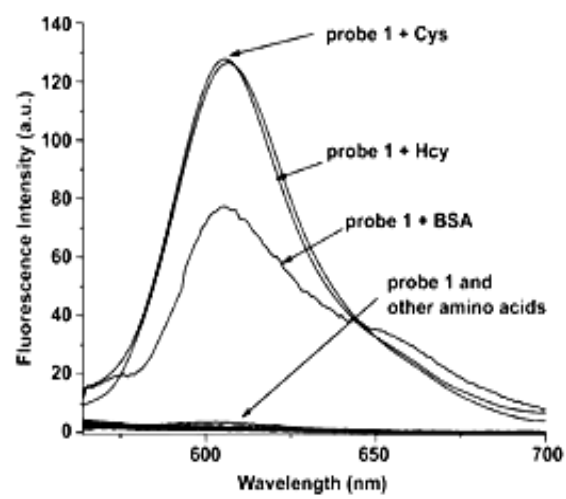

Fig. 11. Emission spectra for probe 29 in the $\mathrm{CH}_{3} \mathrm{CN} /$ $\mathrm{H}_{2} \mathrm{O}\left(8.14 \times 10^{-5} \mathrm{M}, 4: 1, \mathrm{v} / \mathrm{v}, \mathrm{pH} 7.2\right)$ upon addition of various amino acids and proteins (100 equiv). Reproduced with permission from ref. 36. Copyright (2013) John Wiley \& Sons

Confocal luminescence imaging studies revealed that probe 29 was able to detect the changes in the concentration of Cys/Hcy in the HeLa living cells (Figure. 12).
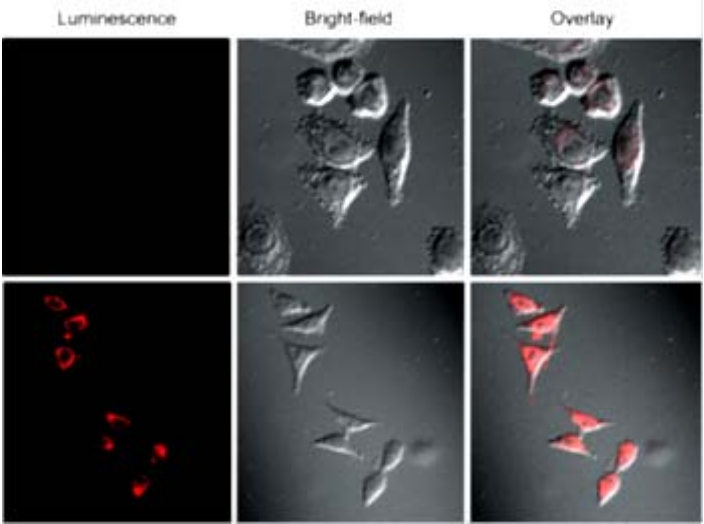

Fig. 12. Luminescence images of probe 29 in Hela cells. a) Hela cells incubated with $200 \mathrm{~mm}$ $\mathrm{N}$-ethylmaleimide for $30 \mathrm{~min}$ and then further incubated with $29(20 \mathrm{~mm})$ for $30 \mathrm{~min}$. b) Hela cells incubated with $29(20 \mathrm{~mm})$ for $30 \mathrm{~min}$. Reproduced with permission from ref. 36. Copyright (2013) John Wiley \& Sons

By modulating the structure of iridium complex, Mao and coworkers first studied the 
emission glutamine sensing and imaging in live cells $^{37}$. They prepared a iridium complex containing aldehyde group $\left[\mathrm{Ir}(\mathrm{pba})_{2}(\mathrm{DMSO})_{2}\right]-\mathrm{PF}_{6}(\mathrm{Hpba}=4-$ (2-pyridiyl)benzaldehyde), (30) by the treatment of
iridium(III) precursor $\left[(\mathrm{pba})_{2} \operatorname{Ir}(\mu-\mathrm{Cl})_{2} \operatorname{Ir}(\mathrm{pba})_{2}\right]$, which was obtained by heating the reaction mixture of $\mathrm{IrCl} \cdot 3 \mathrm{H}_{2} \mathrm{O}$ and $\mathrm{Hpba}$, with DMSO in the presence of $\mathrm{KPF}_{6}$ (Scheme 14).

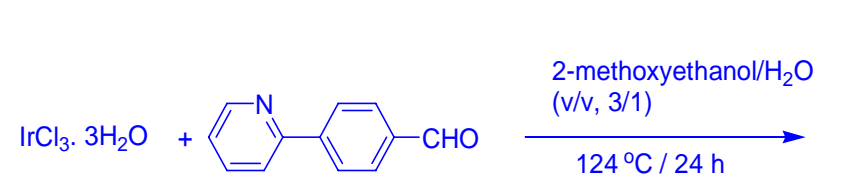

$124^{\circ} \mathrm{C} / 24 \mathrm{~h}$

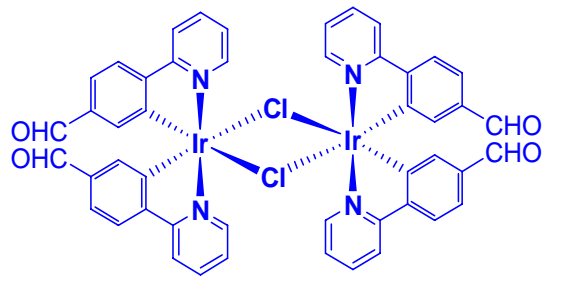

Dimer 1; Yield $=92.8 \%$
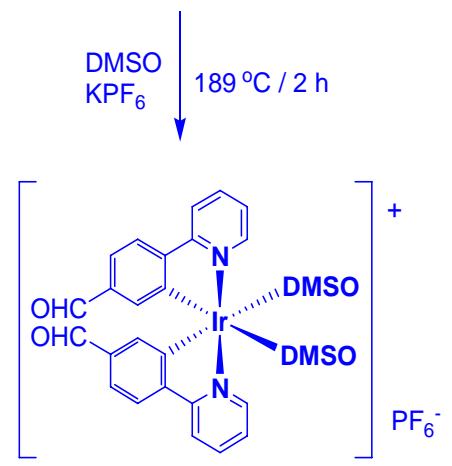

30 , Yield $=65.8 \%$

Scheme 14. Synthesis of cyclometalated iridium(III) complex, 30

Absorption spectrum of 30 exhibited strong absorption bands at 274-324 nm, weak bands at $375-420 \mathrm{~nm}$, and a forbidden band at $650-700 \mathrm{~nm}$, corresponding to the ${ }^{1} \mathrm{IL}\left(\pi \rightarrow \pi^{\star}\right)$ (pba)), ${ }^{1} \mathrm{MLCT}$ (d $\pi(\mathrm{Ir})$ $\rightarrow \pi^{*}\left(\mathrm{pba}^{\prime}\right)$ and ${ }^{3} \mathrm{MLCT}\left(\mathrm{d} \pi(\mathrm{Ir}) \rightarrow \pi^{*}(\mathrm{pba})\right.$ transitions, respectively. Compound 30 was weakly luminescent at $557 \mathrm{~nm}$ with a lifetime of $100 \mathrm{~ns}$, and a quantum yield of 0.04 due to the quenching of emission by electron-withdrawing pba moiety, which is supported by DFT calculations. Addition of Glutamine (Gln) into 30 resulted in the decrease of emission intensity at $557 \mathrm{~nm}$ initially, but a new peak at $475 \mathrm{~nm}$ was generated and increased with a blue of shift of $82 \mathrm{~nm}$ (Fig. 13). A maximum increase of 200 times in the emission intensity of 30 at $475 \mathrm{~nm}$ was registered at 0 to $800 \mu \mathrm{M}$ of Gln. Other amino acids and Gln-containing peptides did not induce any noticeable changes in the emission spectra of 30. This result demonstrated that complex 30 displayed a high sensitivity and selectivity for GIn. In addition, the DFT calculation and MS spectrometry studies supported the formation of highly emissive 30-Gln complex.
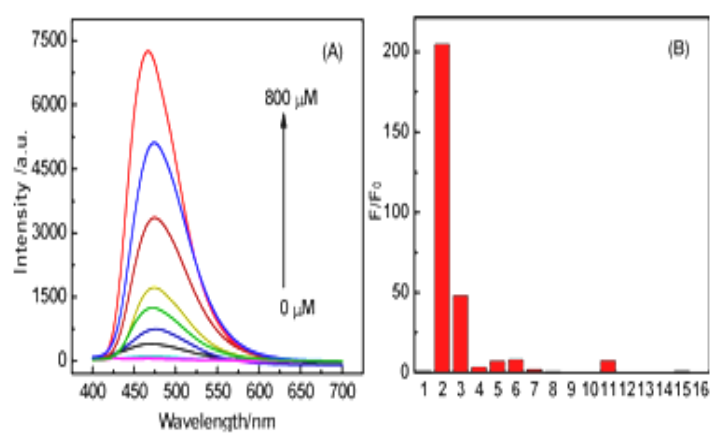

Fig. 13. (A) Emission spectra of 30 solution (10 mM in DMSO/PBS, $v / v=1 / 49$ ) in the presence of increased concentrations of GIn (from bottom to top: 0 , $10,20,40,60,80,100,200,400,600$, and $800 \mu \mathrm{M})$; (B) Selective GIn detection using 30. Fluorescence responses $\left(F / F_{0}\right)$ of $30(10 \mathrm{mM}$ in DMSO/PBS, $v / v=$ $1 / 49)$ to various amino acids $(800 \mu \mathrm{M})$ and $\mathrm{GIn}$ containing peptides $(800 \mu \mathrm{M})$ (from left to right were 1, 30; 2, GIn; 3, Arg; 4, Ala; 5, Asp; 6, Asn; 7, His; 8, Ile; 9, Cys; 10, Tyr; 11, Lys; 12, Gly; 13, Glu; 14, GSH; 15, Ala"GIn; and 16, Gly"GIn. Reproduced with permission from ref. 37. Copyright (2016) American Chemical Society 
Complex 30 treated HeLa cells showed a 600-times stronger emission in cytoplasm compared to nucleus. In addition, emission of 30 was further enhanced upon incubation of these cells with Gln (Fig. 14). A high level of co-localization of 30 and mitochondria in which glutamine is an important energy source, was also demonstrated using co-staining with rodamine123. These studies revealed that complex 30 can be a potential platform in studying mitochondrial metabolism.

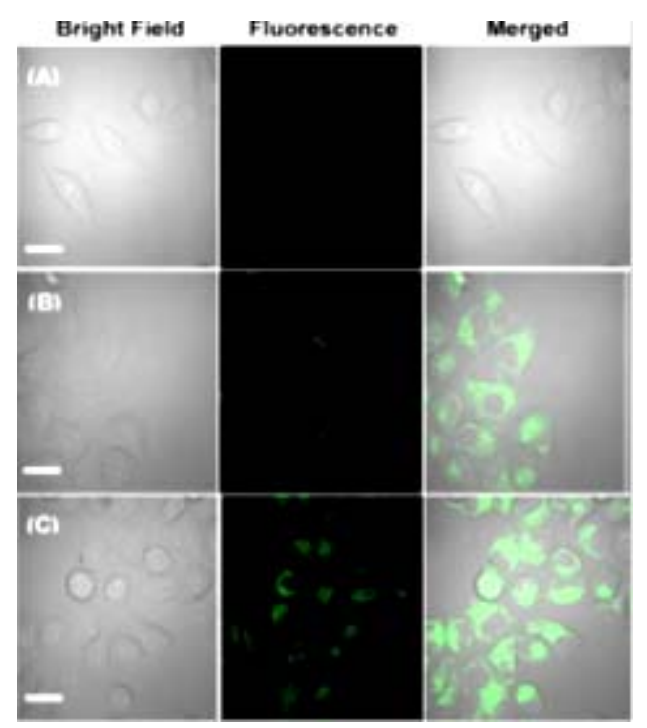

Fig. 14. CLSM and bright-field images of HeLa cells (A) without any treatment; (B) incubated with $20 \mu \mathrm{M}$ 30 in DMSO/PBS (pH 7.0, 1/49, v/v, $10 \mathrm{mM}$ ) for $1 \mathrm{~h}$ at $37^{\circ} \mathrm{C}$. (C) Pre-incubated with $800 \mu \mathrm{M}$ GIn for $1 \mathrm{~h}$, then incubated with $20 \mu \mathrm{M} 30$ in DMSO/PBS (pH 7.0, $1 / 49, \mathrm{v} / \mathrm{v}, 10 \mathrm{mM})$ for $1 \mathrm{~h}$ at $37^{\circ} \mathrm{C}\left(\lambda_{\text {ex }}: 405 \mathrm{~nm}, \lambda_{\text {em }}: 425-470\right.$ nm). Scale bar: $20 \mu \mathrm{m}$. Reproduced with permission from ref. 37. Copyright (2016) American Chemical Society
Mao and coworkers ${ }^{38}$ employed a redox strategy for the detection of thiol amino acid using iridum(III) complex, 31 (Scheme 15). Treatment of $\left[\operatorname{lr}(\mathrm{ppy})_{2}\right]_{2} \mathrm{Cl}_{2}$ (ppy $=2$-phenylpyridine) with and 1 , 10-phenanthroline-5,6-dione (phendione) in a $\mathrm{CH}_{2} \mathrm{Cl}_{2}: \mathrm{MeOH}$ mixture under reflux condition resulted in the formation of $\left[\operatorname{lr}(\mathrm{ppy})_{2}\right.$ (phendione)] $\left(\mathrm{PF}_{6}\right)$ (31). Upon excitation at $350 \mathrm{~nm}$, compound 31 displayed an emission at $587 \mathrm{~nm}$, which is Stokes shifted by $237 \mathrm{~nm}$, with a lifetime of $4.26 \mu \mathrm{s}$.

In the absence of GSH, compound 31 exhibited a weak luminescence, but its emission intensity was approximately 3-fold enhanced with a detection limit of $1.67 \mu \mathrm{M}$, upon the addition of GSH. Job's plot analysis clearly demonstrated a 1:1 binding stoichiometry of complex 31 with GSH. ${ }^{1} \mathrm{H}$ NMR and mass spectrometry analyses confirmed that GSH reduced the phendione $\mathrm{N} \wedge \mathrm{N}$ donor in 31 to afford the emissive complex 32 (Scheme 15). Furthermore, the probe 31 was selective for GSH over Cys and other interfering amino acids.

Recently, Lo and coworkers ${ }^{39}$ prepared three cyclometallated iridium (III) complexes, $\left[\mathrm{Ir}(\mathrm{pq})_{2}\left(\mathrm{~N}^{\wedge} \mathrm{N}\right)\right]\left(\mathrm{PF}_{6}\right)(32 \mathrm{a}-34 \mathrm{a})(\mathrm{Hpq}=2$-phenylquinoline; $N N=4-(\mathrm{N}-(4-(2,4-$ dinitrophenoxy)benzyloxy)carbonyl) aminomethyl-4-methyl-2,2-bipyridine (bpy-dinitro1) (32a), 4-(2,4-dinitrophenoxy)methyl-4-methyl2,2-bipyridine (bpy-dinitro-2) (33a), 4-(4-(2,4dinitrophenoxy)phenyl)-2,2-bipyridine (bpy-dinitro-3) (34)), by the reaction of $\left[\mathrm{Ir}_{2}(\mathrm{pq})_{4} \mathrm{Cl}_{2}\right]$ with their corresponding bpy-dinitro derivatives in $\mathrm{CH}_{2} \mathrm{Cl}_{2} / \mathrm{MeOH}$ mixture at room temperature and examined their intracellular thiol sensing ability (Scheme 16).

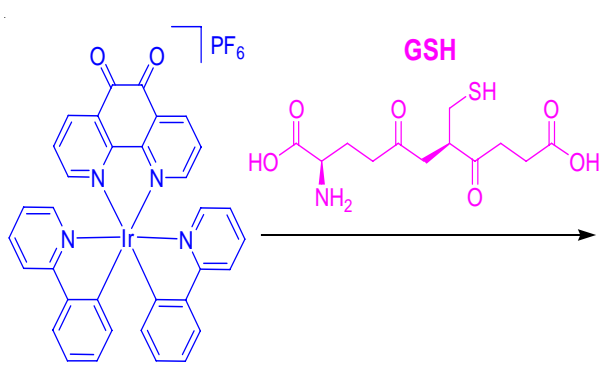

31

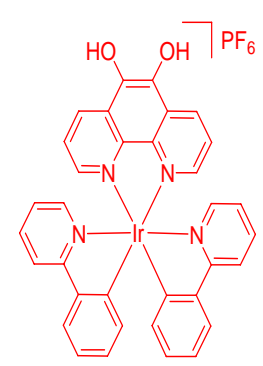

32<smiles>NC(CCC(=O)NC(CSSCC(NC(=O)CCC(N)C(=O)O)C(=O)NCC(=O)O)C(=O)NCC(=O)O)C(=O)O</smiles>

GSSG

Scheme 15. Mechanism of GSH detection by iridium(III) complex 31 while GSSG is oxidized by glutathione 


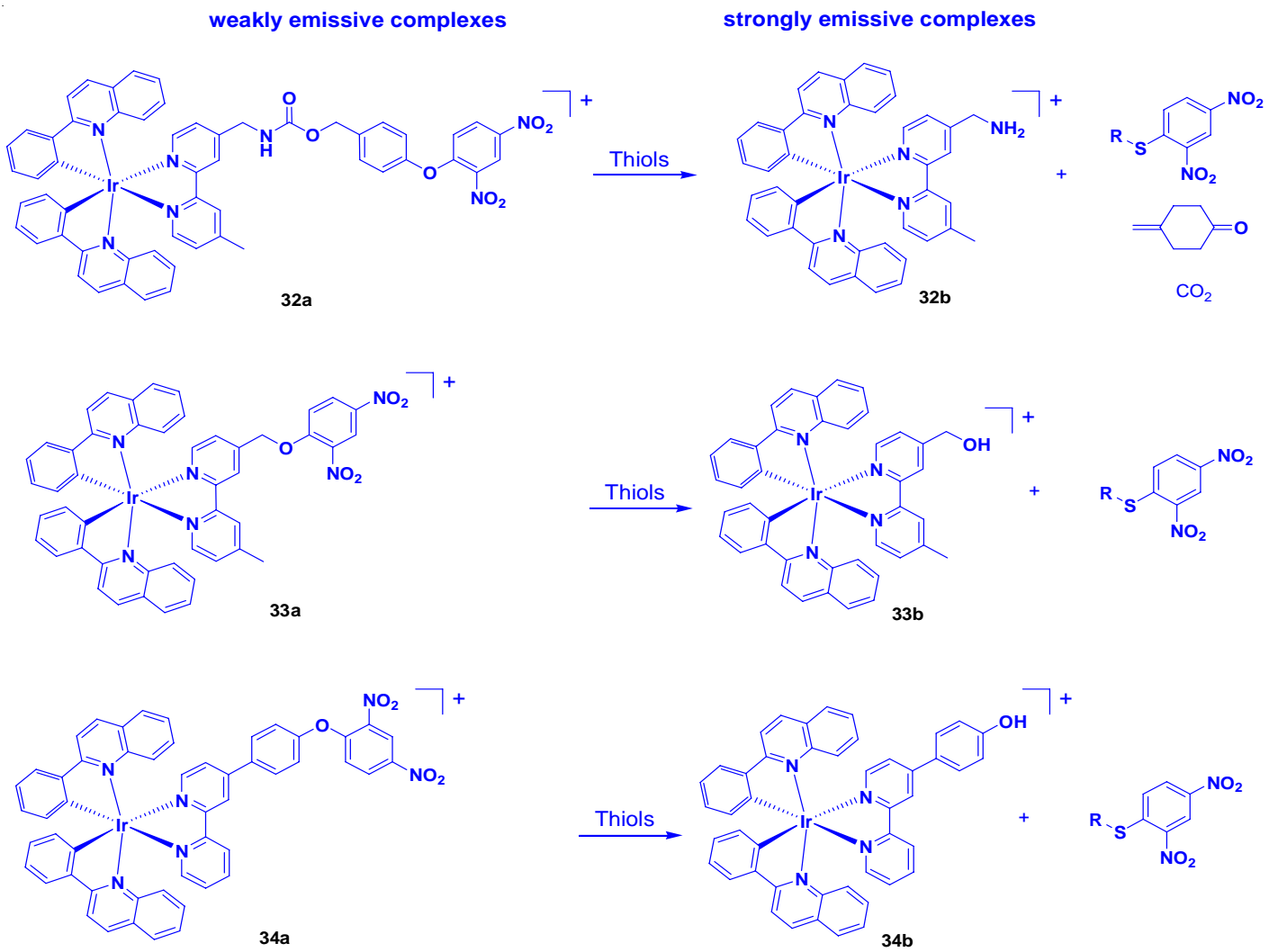

Scheme 16. Thiolysis of complexes $32 a-34 a$ leading to the formation of complexes $32 b-34 b$, respectively

These complexes showed an intraligand $\left(\pi \rightarrow \pi^{\star}\right)\left(\mathrm{N}^{\wedge} \mathrm{N}\right.$ and $\left.\mathrm{pq}\right)$ absorption features at 256$309 \mathrm{~nm}$, and ${ }^{1} \mathrm{MLCT}\left(\mathrm{d} \pi(\mathrm{Ir}) \rightarrow \pi^{*}\left(\mathrm{~N}^{\wedge} \mathrm{N}\right.\right.$ and $\left.\left.\mathrm{pq}\right)\right)$ transition at $310-449 \mathrm{~nm}$ while their forbidden ${ }^{3} \mathrm{MLCT}$ $\left(\mathrm{d} \pi(\mathrm{Ir}) \rightarrow \pi^{\star}\left(\mathrm{N}^{\wedge} \mathrm{N}\right.\right.$ and $\left.\left.\mathrm{pq}\right)\right)$ transition as tailing was observed beyond at $450 \mathrm{~nm}$. Complexes 32a-34a featured a weak emission at 551-555 nm with a shoulder at 588-602 $\mathrm{nm}$ in $\mathrm{CH}_{2} \mathrm{Cl}_{2}$ because of quenching by the dinitrophenyl moiety. Therefore, the observed emission came from ${ }^{3} \mathrm{~L} L\left(\pi \rightarrow \pi^{*}\right)(\mathrm{pq})$ of these complexes. A maximum increase of 2.3-fold in the emission intensity of $32 \mathrm{a}$ or $34 \mathrm{a}$ was registered upon incubation with $\mathrm{GSH}$ or $\mathrm{Na}_{2} \mathrm{~S}(\mathrm{a}$ common source of $\mathrm{H}_{2} \mathrm{~S}$ ) in $\mathrm{KPi}$ buffer/MeOH. Whereas compound 33 a gave a minimal enhancement because of the presence of shorter linker that might lead to steric effect between thiols and dinitroaromatic moiety. ESI-MS analysis supported the formation of their respective complexes 32b-34b after thiolysis, confirming that the emission enhancement occurred after leaving the quenching motif.
As these complexes did not respond to biologically relevant RSS $\left(\mathrm{SO}_{3}^{2-}, \mathrm{S}_{2} \mathrm{O}_{3}{ }^{2-}\right.$, and $\left.\mathrm{NCS}^{-}\right)$, RNS such as hydrogen peroxide $\left(\mathrm{H}_{2} \mathrm{O}_{2}\right)$, peroxide ( $t \mathrm{BuOOH}$ and $\left.\mathrm{O}_{2}^{-}\right)$, nitrate $\left(\mathrm{NO}_{3}^{-}\right)$, and nitrite $\left(\mathrm{NO}_{2}^{-}\right)$, they are considered as good candidates for sensing thiols selectively. When compound 32 a was incubated with $\mathrm{Na}_{2} \mathrm{~S}$ treated HeLa cells, they showed a bright emission in comparison to the cells without pre-treatment of $\mathrm{Na}_{2} \mathrm{~S}$. However, a significant weak emission in the cells without pre-treatment of $\mathrm{Na}_{2} \mathrm{~S}$ was observed due to the presence of endogenous GSH. However, the use of NEM, a common GSH scavenger, made the weakening the emission of complex 32a stained HeLa cells. In another experiment, upon incubation of complex 32a stained HeLa cells with GSH-ester, a bright emissive staining in the cytoplasm region, majority of GSH localized here, was observed. These results demonstrated that complex 32a acted as an effective sensor for GSH and $\mathrm{H}_{2} \mathrm{~S}$ in living cells. 


\section{Platinum(II) complexes}

The use of alkynyl-platinum compounds generates highly stable coordination complexes with DNA and amino acids. Huang et al., ${ }^{40}$ prepared two platinum complexes, $\mathrm{Pt}($ phen $)\left(\mathrm{C}^{\circ} \mathrm{CC}_{6} \mathrm{H}_{5} \mathrm{CHO}\right)_{2}$
(35) and $\mathrm{Pt}($ phen $)\left(\mathrm{C}^{\circ} \mathrm{CC}_{6} \mathrm{H}_{5}\right)_{2}$ (36) by the reaction of $\mathrm{Pt}$ (phen) $\mathrm{Cl}_{2}$ and 4-ethynylbenzaldehyde or phenylacetylene, respectively, in the presence of Cul and diethylamine in dichloromethane and used them for cysteine sensing (Scheme 17).

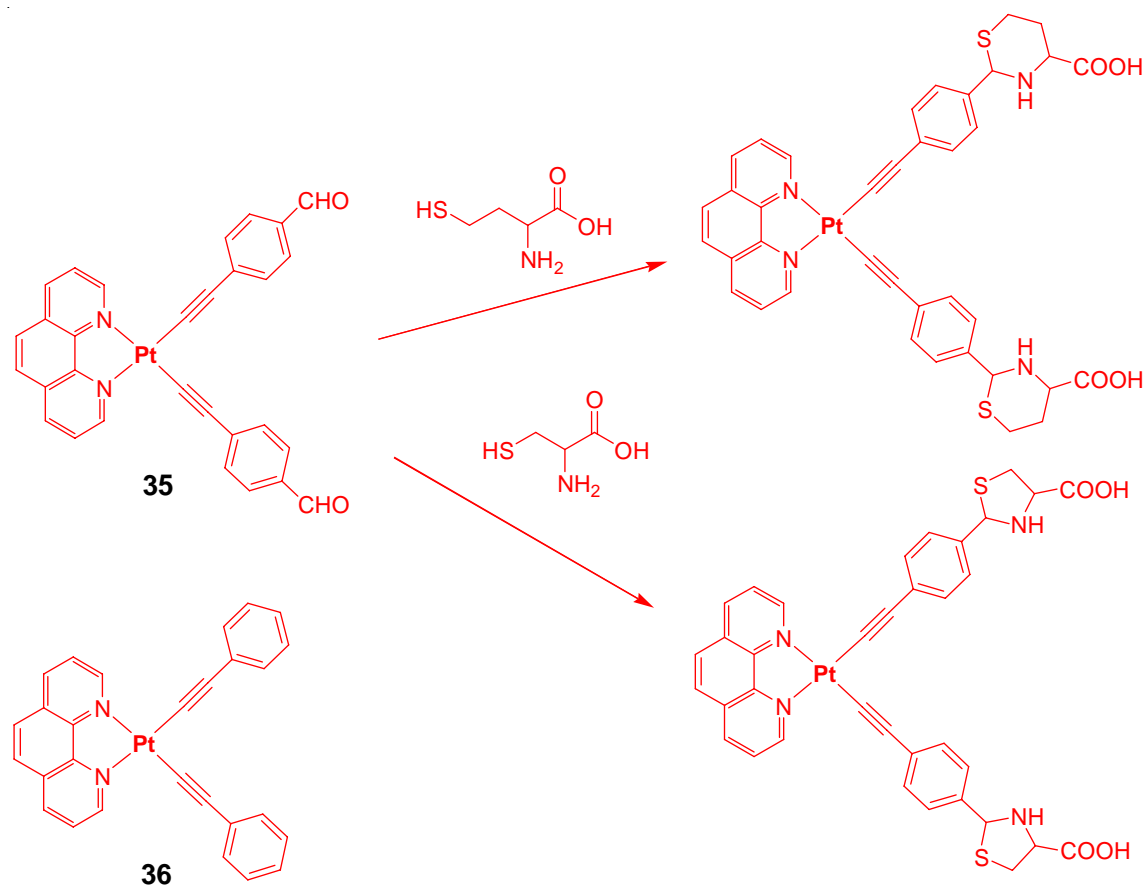

Scheme 17. The chemical structures of compounds 35 and 36 and the probable
sensing mechanism of 35 towards Hcy and Cys

Absorption spectra of 35 and 36 displayed several bands below at 400 and a wide band centered at $400 \mathrm{~nm}$, which are ascribed to MLCT and diamine and acetylide-based intra-ligand transitions, respectively. Compound 36 showed an orange emission at $560 \mathrm{~nm}$ but compound 35 showed a green emission at $510 \mathrm{~nm}$, which is blue-shifted to $50 \mathrm{~nm}$ indicating the presence of electron withdrawing aldehyde group in 35. The addition of Hcys dramatically quenched the emission band of 35 at $510 \mathrm{~nm}$ followed by redshifted to $555 \mathrm{~nm}$ along with changing color from green to orange. However, other amino acids did not induce any noticeable changes in the emission spectrum of 35 , confirming high selectivity towards Cys/Hcys. Time dependence studies supported that the reaction was complete within $120 \mathrm{~min}$. upon interacting 35 with Cys/Hcys. The selective interaction of 35 with Cys/Hcys was also confirmed by ${ }^{1} \mathrm{H}$ NMR and DFT analyses. Finally, the authors concluded that formation of thiazinane led to quenching of 35 along with a red-shifted emission through the reaction of 35 with Cys/Hcys.

Through a self-destructive mechanism, a turn-on fluorescent sensing of thiol containing amino acids using platinum(II) cage compounds has been reported ${ }^{41}$. Three tetragonal prismatic $\mathrm{Pt}(\mathrm{II})$ metallacages $37 \mathrm{a}-37 \mathrm{c}$ were prepared by the reaction of $\mathrm{Pt}(\mathrm{II})$ acceptors with dipyridyl and tetraphenylethene (TPE)-based sodium benzoate ligands in acetone/water mixture via a metal-coordination driven self-assembly process (Scheme 18). The formation of these cages were confirmed by NMR, ESI-TOF, UV-Vis absorption and fluorescence spectral studies.

In different polar aprotic solvents, cages $37 \mathrm{a}$ and $37 \mathrm{~b}$ showed TPE derivative based absorption bands in the range of $350-370 \mathrm{~nm}$, while 
cage 37c displayed BODIPY chromophore based absorption band at $520 \mathrm{~nm}$ along with the absorption band of TPE derivative. Cages $37 a$ and $37 b$ exhibited a strong fluorescence at around $493 \mathrm{~nm}$, corresponding to the TPE emission but cage 37c showed two emission peaks at 472 and $544 \mathrm{~nm}$, corresponding the TPE and BODIPY emission, respectively.

Cage $37 \mathrm{~b}$ was non-emissive in methanol/ water mixture. However, the addition of thiol containing amino acids such as glutathione and cysteine concomitantly increased the intensity of cage $37 \mathrm{~b}$ at $500 \mathrm{~nm}$ with the detection limits in the range of $1.89 \times 10^{-7}$ and $2.78 \times 10^{-7} \mathrm{M}$, respectively (Fig. 15). However, other amino acids included glycine, alanine, arginine, lysine, serine, leucine, isoleucine, glutamate, and histidine did not response. This result demonstrated the potential application of cage $37 \mathrm{~b}$ as a sensor in thiolcontaining amino acids.
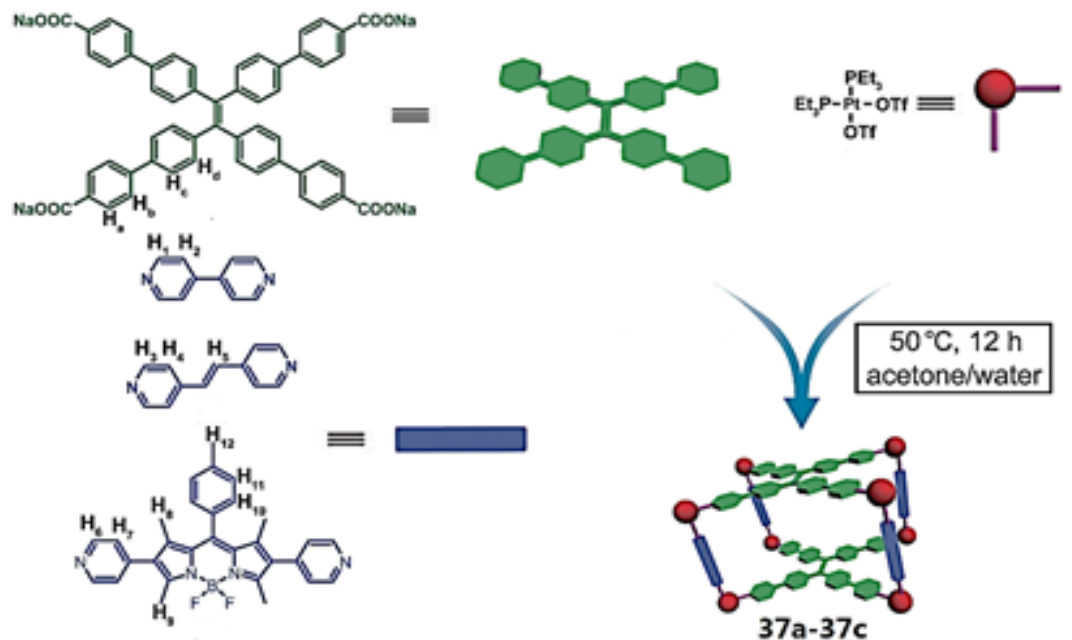

Scheme 18. Synthetic routes and cartoon representations of cages 37a-37c. Reproduced with permission from ref. 41. Copyright (2017) American Chemical Society
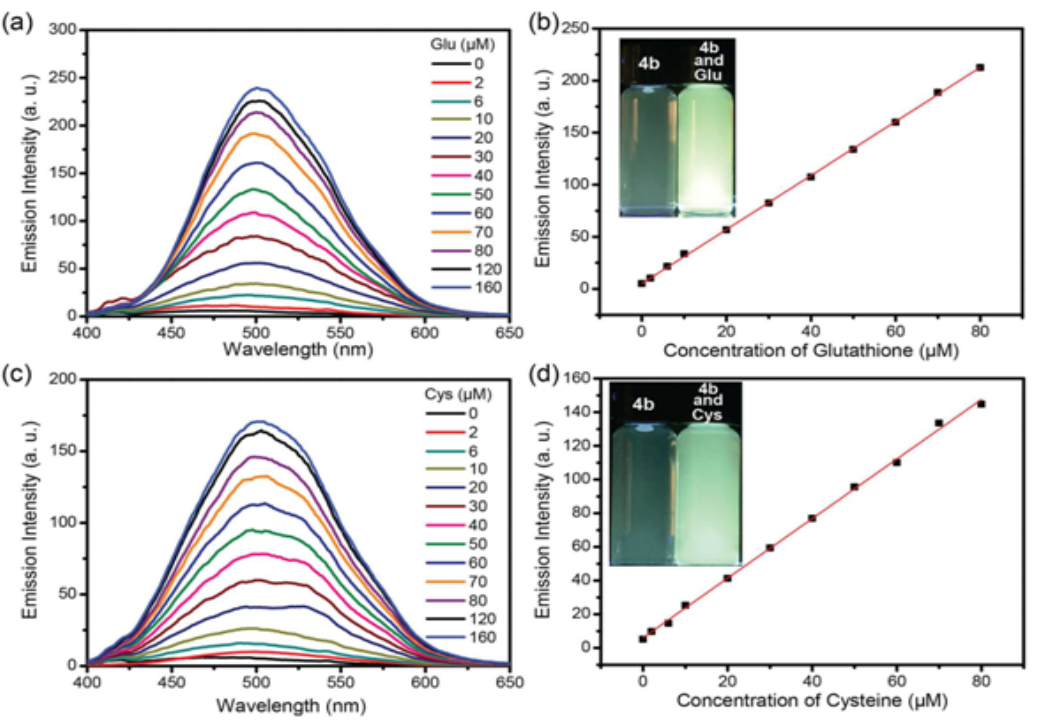

Fig. 15. Fluorescence spectra of cage $37 \mathrm{~b}(10 \mu \mathrm{M})$ after 5 min upon the addition of increasing concentrations of glutathione (a) and cysteine (c) and the emission intensities at $500 \mathrm{~nm}$ as a function of glutathione (b) and cysteine (d) concentration. Each spectrum was collected in methanol/water $(1 / 1, \mathrm{v} / \mathrm{v})$ with $\lambda_{\text {ex }}=365 \mathrm{~nm}$. Insets: photographs of $10 \mu \mathrm{M}$ cage $37 \mathrm{~b}$ before (left) and after (right) the addition of $160 \mathrm{iM}$ thiol-containing amino acids in methanol/water (1/1, v/v) upon excitation at $365 \mathrm{~nm}$ using a UV lamp at $298 \mathrm{~K}$. Reproduced with permission from ref. 41. Copyright (2017) American Chemical Society 
${ }^{1} \mathrm{H}$ NMR titration analysis revealed that thiol amino acids decomposed cage 37b to form mononuclear Pt-aminoacid complexes along with benzoic acid derived TPE ligand when cysteine or glutathione was added to a DMSO solution of 37b. ${ }^{31} \mathrm{P}\left\{{ }^{1} \mathrm{H}\right\}$ NMR study confirmed the destruction of $37 \mathrm{~b}$ upon the addition of these amino acids. A 1:1 binding isotherm was found in the complexation between $\mathrm{Pt}\left(\mathrm{PEt}_{3}\right)_{2}(\mathrm{OTf})_{2}$ and amino acids. Moreover, the regeneration of cage was observed while adding $\mathrm{Pt}(\mathrm{II})$ acceptors, indicating the thermodynamic stability of the Pt-amino acid complexes compared to that of cage. However, cage $37 \mathrm{~b}$ remained stable even after the addition of 2-mercaptoethanol. This result clearly demonstrated that both thiol and the carboxylic groups performed to function as coordinative ligands with $\mathrm{Pt}(\mathrm{II})$ center. As the free TPE derivative was emissive, it functioned as an indicator for the study of thiol-containing amino acids sensing. Based on these results, the authors proposed a self-destructive mechanism for the sensing of $\mathrm{Pt}$ (II) caged compounds towards thiol amino acids (Scheme 19).

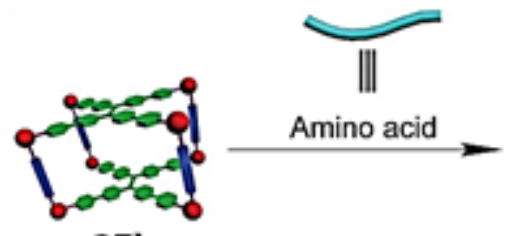

$37 \mathrm{~b}$

Non-emissive
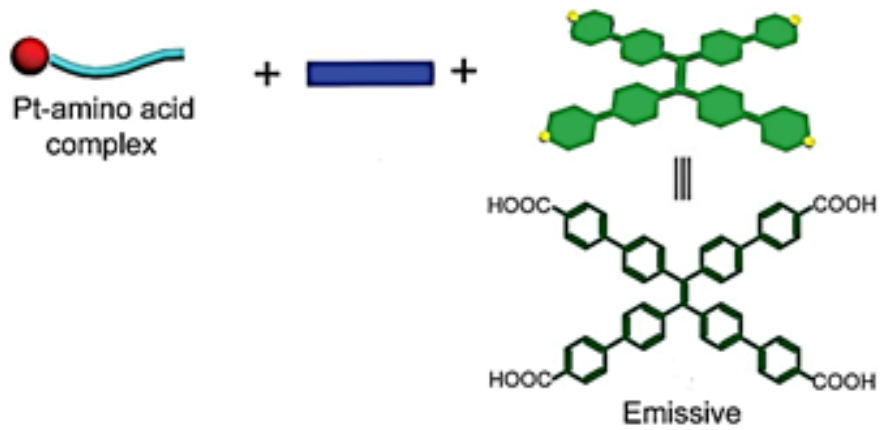

Scheme 19. Cartoon representation of the self-destructive mechanism. Reproduced with permission from ref. 41. Copyright (2017) American Chemical Society

\section{CONCLUSION}

In this review, we have highlighted a series of phosphorogenic heavy metal sensors for the detection of thiol amino acids based on the previously published works. These complexes offer a remarkable structural diversity and tunable emission properties that make them luminescent sensors viable alternatives to organic fluorophores. These probes have been successfully utilized for the sensing and bioimaging of amino acids, especially biothiols, by operating turn-on mechanism Via emission enhancement or emission shift (color change) due to electron or energy transfer mechanism. Most of the reported complexes have achieved discrimination between thiolcontaining amino acids Cys, Hcys, and $\mathrm{GSH}$, showing excellent selectivity with the lower detection limit. By predicting the interaction of these complexes with thiols, theoretical studies effectively predict to improve the design of structure of metal complexes. For increasing the solubility of metal complexes, the hydrophilic groups such as quaternary ammonium salt can be incorporated into coordinating ligands of metal complexes and can be used to realize the changes of Cys/Hcys concentration in living cells in aqueous medium.

Inspite of significant improvements in this field, several issues that are affected by various factors need to be improved. It would be highly desirable to rationally design phosphorogenic metal complexes with desired properties that can selectively detect and differentiate not only limited to bithiols but also naturally available amino acids. Addition of minimal organic solvent such as $\mathrm{CH}_{3} \mathrm{CN}$ and DMSO, because of poor solubility of metal complexes, in bioimaging studies leads to be toxic and destroys the cellular functions, which demerits the application of these metal complexes. Therefore, development of new phosphorogenic heavy metal probes with complete water solubility and higher 
selectivity for specific amino acids is an important goal. For bioimaging applications, NIR phosphorogenic heavy metal probes would be highly desirable for the detection of various amino acids in the living cells and tissues because they penetrate very deep with less photodamage and minimum fluorescence background. We envisage that the application of phosphorogenic heavy metal complexes in amino acids sensing will continue to thrive and mature in this field and will show their commercial applications from research laboratories.

\section{ACKNOWLEDGEMENT}

We gratefully acknowledge the financial supports from the Council of Scientific and Industrial Research (CSIR), India and the Academia Sinica, Ministry of Science and Technology, Taiwan.

\section{REFERENCES}

1. Wood, Z. A., Schroder, E., Harris, J. R., and Poole, L. B., Trends Biochem. Sci. 2003, 28, 32-40.

2. Refsum, H., Smtth, A. D., Ueland, P. M., Nexo, E., Clarke, R., Mcpartlin, J., Johnston, C., Engbaek, F., and Schneede, J., Clin. Chem. 2004, 50, 3-32.

3. Shao, N., Jin, J. Y., Cheung, S. M., Yan, R. H., Chan, W. H., and Mo, T., Angew. Chem. Int. Ed. 2006, 45, 4944-4948.

4. Yang, X.-F., Huang, Q., Zhong, Y., Li, Z., Li, H., Lowry, M., Escobedo, J. O., and Strongin, R. M., Chem. Sci. 2014, 5, 2177-2183.

5. Yue, Y., Huo, F., Ning, P., Zhang, Y., Chao, J., Meng, X., and Yin, C., J. Am. Chem. Soc. 2017, 139, 3181-3185.

6. El-Brashy, A. M., and Al-Ghannam, S. M., Pharm. World Sci. 1995, 17, 54-57.

7. Shen, C.-C., Tseng, W.-L., and Hsieh, M.-M. J. Chromatogr. A 2009, 1216, 288-293.

8. Wang, W., Li, L., Liu, S., Ma, C., and Zhang, S., J. Am. Chem. Soc. 2008, 130, 1084610847.

9. Wang, W., Rusin, O., Xu, X., Kim, K. K., Escobedo, J. O., Fakayode, S. O., Fletcher, K. A., Lowry, M., Schowalter, C. M., Lawrence, C. M., Fronczek, F. R., Warner, I. M., and Strongin, R. M. J. Am. Chem. Soc. 2005, 127, 15949-15958.

10. Sato, Y., Iwata, T., Tokutomi, S., and Kandori, H., J. Am. Chem. Soc. 2005, 127, 1088-1089.

11. Dieckhaus, C. M., Fernández-Metzler, C. L., King, R., Krolikowski, P. H., and Baillie, T. A., Chem. Res. Toxicol. 2005, 18, 630-638.

12. Wang, W., Escobedo, J. O., Lawrence, C. M., and Strongin, R. M., J. Am. Chem. Soc. 2004, 126, 3400-3401.

13. Yang, Y., Zhao, Q., Feng, W., and Li, F. Chem.
Rev. 2013, 113, 192-270.

14. Yin, C., Huo, F., Zhang, J., Martinez-Manez, R., Yang, Y., Lv, H., and Li, S., Chem. Soc. Rev. 2013, 42, 6032-6059.

15. Niu, L.-Y.; Chen, Y.-Z.; Zheng, H.-R.; Wu, L.-Z.; Tung, C.-H., and Yang, Q.-Z. Chem. Soc. Rev. 2015, 44, 6143-6160.

16. Wang, J., Liu, H.-B., Tong, Z., and Ha, C.-S., Coord. Chem. Rev. 2015, 303, 139-184.

17. Ma, D.-L., Ma, V. P.-Y., Chan, D. S.-H., Leung, K.-H., He, H.-Z., and Leung, C.-H., Coord. Chem. Rev. 2012, 256, 3087-3113.

18. Zhao, Q., Li, F., and Huang, C., Chem. Soc. Rev. 2010, 39, 3007-3030.

19. Lo, K. K. W., Hui, W. K., Ng, D. C. M., and Cheung, K. K., Inorg. Chem. 2002, 41, 40-46.

20. Amoroso, A. J., Arthur, R. J., Coogan, M. P., Court, J. B., Fernandez-Moreira, V., Hayes, A. J., Lloyd, D., Millet, C., and Pope, S. J. A., New J. Chem. 2008, 32, 1097-1102.

21. Weh, J., Duerkop, A., and Wolfbeis, O. S., ChemBioChem. 2007, 8, 122-128.

22. Ji, S., Guo, H., Yuan, X., Li, X., Ding, H., Gao, P., Zhao, C., Wu, W., Wu, W., and Zhao, J., Org. Lett. 2010, 12, 2876-2879.

23. Zhang, R., Yu, X., Ye, Z., Wang, G., Zhang, W., and Yuan, J., Inorg. Chem. 2010, 49, 7898-7903.

24. Li, M.-J., Zhan, C.-Q., Nie, M.-J., Chen, G.-N., and Chen, X., J. Inorg. Biochem. 2011, 105, 420-425.

25. Zhang, W., Zhang, R., Zhang, J., Ye, Z., Jin, D., and Yuan, J., Anal. Chim. Acta, 2012, 740, 80-87.

26. Zhang, R., Ye, Z. Q., Yin, Y. J., Wang, G. L., Jin, D. Y., Yuan, J. L., and Piper, J. A., Bioconjugate Chem. 2012, 23, 725-733.

27. Li, G.-Y., Liu, J.-P., Huang, H.-Y., Wen, Y., 
Chao, H., and Ji, L.-N., J. Inorg. Biochem. 2013, 121, 108-113.

28. Ye, Z., Gao, Q., An, X., Song, B., and Yuan, J., Dalton Trans. 2015, 44, 8278-8283.

29. Ma, D.-L., Wong, W.-L., Chung, W.-H., Chan, F.-Y., So, P.-K., Lai, T.-S., Zhou, Z.-Y., Leung, Y.-C., and Wong, K.-Y., Angew. Chem. Int. Ed. 2008, 47, 3735-3739.

30. Zhao, N., Wu, Y.-H., Shi, L.-X., Lin, Q.-P., and Chen, Z.-N., Dalton Trans. 2010, 39, 8288-8295.

31. Chen, H. L., Zhao, Q., Wu, Y. B., Li, F. Y., Yang, H., Yi, T., and Huang, C. H., Inorg. Chem. 2007, 46, 11075-11081.

32. Xiong, L., Zhao, Q., Chen, H., Wu, Y., Dong, Z., Zhou, Z., and Li, F., Inorg. Chem. 2010, 49, 6402-6408.

33. Shiu, H.-Y., Wong, M.-K., and Che, C.-M., Chem. Commun. 2011, 47, 4367-4369.

34. Ma, Y., Liu, S., Yang, H., Wu, Y., Yang, C., Liu, X., Zhao, Q., Wu, H., Liang, J., Li, F., and Huang, W., J. Mater. Chem. 2011, 21, 18974-18982.
35. Li, C., Yu, M., Sun, Y., Wu, Y., Huang, C., and Li, F., J.Am. Chem. Soc. 2011, 133, 11231-11239.

36. Tang, Y., Yang, H.-R., Sun, H.-B., Liu, S.-J., Wang, J.-X., Zhao, Q., Liu, X.-M., Xu, W.-J., Li, S.-B., and Huang, W., Chem. Eur. J. 2013, 19, 1311-1319.

37. Jiang, Q., Wang, M., Yang, L., Chen, H., and Mao, L., Anal. Chem. 2016, 88, 10322-10327.

38. Mao, Z., Liu, J., Kang, T.-S., Wang, W., Han, Q.-B., Wang, C.-M., Leung, C.-H., and Ma, D.-L., Sci. Technol. Adv. Mater. 2016, 17, 110-114.

39. Tso, K. K.-S., Liu, H.-W., and Lo, K.K.-W., J. Inorg. Biochem. 2017, 177, 412-422.

40. Huang, K., Yang, H., Zhou, Z., Chen, H., Li, F., Yi, T., and Huang, C., Inorg. Chim. Acta 2009, 362, 2577-2580.

41. Zhang, M., Saha, M. L., Wang, M., Zhou, Z., Song, B., Lu, C., Yan, X., Li, X., Huang, F., Yin, S., and Stang, P. J., J. Am. Chem. Soc. 2017, 139, 5067-5074. 